\title{
TCOM \\ From citizen science to citizen action: analysing the potential for a digital platform to cultivate attachments to nature
}

\section{Nirwan Sharma, Sam Greaves, Advaith Siddharthan, Helen B. Anderson, Annie Robinson, Laura Colucci-Gray, Agung Toto Wibowo, Helen Bostock, Andrew Salisbury, Stuart Roberts, David Slawson and René van der Wal}

\begin{abstract}
Identifying private gardens in the U.K. as key sites of environmental engagement, we look at how a longer-term online citizen science programme facilitated the development of new and personal attachments of nature. These were visible through new or renewed interest in wildlife-friendly gardening practices and attitudinal shifts in a large proportion of its participants. Qualitative and quantitative data, collected via interviews, focus groups, surveys and logging of user behaviours, revealed that cultivating a fascination with species identification was key to both 'helping nature' and wider learning, with the programme creating a space where scientific and non-scientific knowledge could co-exist and reinforce one another.
\end{abstract}

Keywords

DOI

Citizen science; Environmental communication; Public understanding of science and technology

https://doi.org/10.22323/2.18010207

Submitted: 4th April 2018

Accepted: 5th December 2018

Published: 17th January 2019

Introduction:

gardens as sites

for human-nature relationships
The immense scale at which urbanisation has taken place is adversely impacting both the natural environment and human health [Goddard, Dougill and Benton, 2010; Bratman et al., 2015]. In this context, with much of the land modified for urban human consumption, gardens - both public and private - are a key component of urban environments and play an increasingly important role in biodiversity conservation [Davies et al., 2009; Baldock et al., 2015; Threlfall et al., 
2015]. In the U.K., private garden spaces are accessible by an estimated 22.7 million households (87\% of homes), covering a total area of around 433,000 hectares [Davies et al., 2009]. Gardens are thus sites where people consciously become exposed to - and interact frequently with - large networks of non-human species and may thus enable us to evaluate the effects of human behaviours on these networks.

In this study, we examine a digital citizen science platform used in conjunction with 'gardening', thereby focussing on people's development of personal understandings of nature, engagement with environmental concerns and the taking of actions towards biological conservation. Our findings add to the current literature in citizen science by exploring the potential for a significant philosophical, cultural and practical shift to occur in the community of users, from being 'detached observers' to 'active participants' in the world [Ingold, 2000].

\subsection{Beyond binary distinctions}

Recent debates in the philosophy of knowledge, and across many disciplines, from physics to anthropology, have thrown into serious doubt the claim that one single natural world exists onto which different cultures project their own relative views. Rather, entirely different conceptual worlds exist between and within human groups, referred to as 'ontologies': a re-appropriated philosophical term capturing how the world is for people, rather than how people see the world [de Castro, 1998]. In particular, binary Western ontologies that frame 'nature' as something separated from the human realm ('culture') have come under heavy criticism [e.g. Descola, 1996; de Castro, 1998; Ingold, 2000; Tsing, 2015]. Nature-culture distinctions often portray the natural world as a resource-provider for human exploitation: a world that must be tamed, managed and controlled, rather than something that humans are part of and collaborate with [D. J. Haraway, 2008]. This position has created widespread environmental problems that threaten humans and non-humans alike. Whilst it is well-documented that many cultures do not understand humans and the natural world to be separate entities [e.g. Descola, 1996; Kopenawa and Albert, 2013], it is still widely assumed that for the majority of populations in the Western world, there is a clear distinction between the two that makes conservation action problematic [Büscher and Igoe, 2013; Duffy, 2015; Sullivan, 2016].

Environmental citizen science projects typically address conservation issues with the gathering of data about features of the natural environment (e.g. number and distribution of species, ecological indicators). These fast-expanding sets of initiatives take advantage of the ubiquitous nature of smartphones and internet-enabled devices to engage citizens and lay people in large-scale projects involving the collection of data at a local level [Arts, van der Wal and Adams, 2015]. This approach, however, contends with the difficulty of handling the lay/expert interface, due to the need for users to develop scientific expertise while retaining interest in the project [van der Wal et al., 2016]. Another approach is to re-focus citizen science towards citizens' actions [Baptista, Reis and de Andrade, 2018], for example by engaging citizens in everyday practices while pursuing activities of biological recording. In the latter approach, citizen science initiatives are construed as 'hybrid spaces' in which environmental knowledge and skills are 
pursued alongside common activities, such as walking and noticing, stimulation of sensorial attention and affective behaviours [Gray and Colucci-Gray, 2018]. Affect is hereby understood as the "power to affect and be affected" [Massumi, 2015], and to be an autonomous force which, when embedded within social relationships, can be transformative [Ahmed, 2010]. Hence, here we view digital tools not simply as a means to 'detect and identify' species, but also to enhance perceptive abilities for those people who are less accustomed to observing non-human life. By focussing on perception and attention we thus build on current understandings of learning as profoundly 'affective and embodied', according to which cognition is extended across the continuity of mind, body-movement and the environment. In this framework, digital tools are not presented as 'techno-enhancements' to replace bodily experiences but as technologies that may act as a form of 'extended body-mind' [Gray and Colucci-Gray, 2018], to intensify interaction and challenge dualistic ontologies of human/non-human life which are culturally embedded.

\subsection{Context of the study: citizen science and the decline of pollinators}

One area of conservation concern which is increasingly targeted by citizen science initiatives is the widespread decline of pollinating insects [Goulson, 2010; Vanbergen et al., 2014]. Ongoing key threats are numerous but include the loss and fragmentation of habitat through residential and commercial development and agriculture, widespread pesticide use and disease [Dicks, Showler and Sutherland, 2010; Potts et al., 2010]. Both bumblebees and honeybees are popular pollinating insects within British culture. They exhibit a range of qualities desirable to humans, and human-bee comparisons are commonly used by scientists, artists, gardeners and politicians throughout Western culture [Moore and Kosut, 2013]. As a result of this non-human charisma [Lorimer, 2007], the issues that affect bees often appear in the public sphere, with the widely acknowledged narrative of the noble bumblebee working up against human-induced environmental ruin. Through leveraging a narrative that is already widely-recognised, digital platforms may thus be able to engage large groups of people in environmental conservation, and in so doing reach beyond a single charismatic, politicised species.

Specifically, with respect to the decline of pollinators, various interventions have been proposed, some of which target the general public such as planting 'pollinator-friendly' plants, providing insect boxes, leaving areas of gardens unmanaged and preventing pesticide use [Baldock et al., 2015; Hall et al., 2017]. Bumblebees, an important pollinator species group visible to the general public due to their pervasiveness in urban areas [Cameron et al., 2011; Vanbergen et al., 2014], can particularly benefit from public support. Providing larger stands of 'pollinator-friendly' plants in urban green spaces will attract those insects, while heavily modified garden plants are not frequented as pollen or nectar is either not produced by those plants or not accessible by bumblebees [Comba, Corbet, Hunt et al., 1999; Comba, Corbet, Barron et al., 1999; Pawelek et al., 2009].

\subsection{Citizen science in the garden space}

Turning from conservation to gardening, this study will consider how citizen science initiatives can be developed as part of what is already a highly popular and predominantly personal activity. Differently from just volunteering data, gardening 
may allow people to develop close relationships with - and understandings of - local nature [Miller, 2005; Clayton, 2007]. Furthermore, the task of enabling citizens to see themselves as embedded within — rather than separated from - their natural environments is tantamount to creating an environmentally-conscious population [Collard, Dempsey and Sundberg, 2015; D. Haraway, 2016; Tsing, 2017]. However, social analyses of gardens have until very recently depicted the space as a 'grass carpet' [Chevalier, 2002] that is an extension of the domestic space of the home, where plants exist as mere furnishings and animals as relatively benign visitors rather than creatures with their own agency that are understood to have their own preferences, motivations and desires [Degnen, 2009; Hitchings, 2003].

As important sites of biodiversity, gardens may provide key sites for citizen science projects; yet the resulting data gathered by gardeners, and knowledge derived from this, is rarely fed back to members of the public in a usable manner. To address this deficiency, we developed interactive technologies with a view to facilitate the exchange of knowledge and information about gardening, planting for pollinating insects, and specific 'actions' that may enhance the occurrence of bumblebees in gardens. The resulting platform, Planting for Pollinators, emerged through the partnership of ecologists, computing scientists, social scientists and practitioners, and was embedded within BeeWatch, a U.K. citizen science programme operational since 2012, which allows participants to submit photos of bumblebees and learn to identify bumblebee species through online training and automated personalised feedback. The embedding provided two additional BeeWatch 'functionalities', namely: i) to explore the emerging data on bumblebee species-specific use of food plants; and ii) to obtain associated pollinator-friendly gardening advice.

At one level, the research focussed on the various functionalities and 'data-driven pollinator information' and their usefulness to the platform users. At another level, the research looked more broadly at the role of the interface in promoting knowledge exchange and learning about conservation matters amongst different communities, as well as the critical role of the digital experience in adopting new practices by gardeners with different levels of expertise.

Data were collected via interviews, focus groups, surveys, and the logging of user behaviour on the BeeWatch website, thereby obtaining a rich understanding of digital tool use with notable relevance to online citizen science programmes. Our findings show that digital platforms such as BeeWatch hold considerable potential for not only improving knowledge and skills, but also for cultivating non-binary ontologies of nature. These were constituted by a new understanding of the lives of wildlife and an awareness of the complexity of the ecosystems they were part of and led to an unexpectedly large-scale shift towards wildlife-friendly gardening practices, as well as an attitude change in volunteers.

\subsection{The BeeWatch platform and its features}

BeeWatch is primarily a photo submission platform, where interested members of the public submit pictures of bumblebees, use an online identification key to identify the species, and receive machine-generated formative feedback on their identification after the photo has been verified. Verification is either conducted 
by a bumblebee expert or through the use of a crowdsourcing model that seeks consensus among other BeeWatch users [Siddharthan et al., 2016]. Offering participants the possibility to identify bumblebee species in the photos submitted by others helps them to improve their identification skills whilst this reduces the workload of the programmes' bumblebee experts [Siddharthan et al., 2016]. The website also features a training tool, through which users can practice their identification skills on verified photos and receive immediate formative feedback. Besides the required photo-uploading, BeeWatch collects standard 'biological recording' information such as date and location, but also ecological information including the 'food plant' used by the photographed bumblebee specimen, which although not obligatory most users filled out. The latter data was used to create a bottom-up (i.e. user-generated) pollinator-friendly plant database containing species-specific food sources for each bumblebee species. Ecological information for all listed plants (e.g. flowering season, flower colour) and bumblebees (e.g. foraging range, nesting habits) was extracted from key sources and added to the data base.

\subsubsection{Interactive interfaces for accessing data on plant-bumblebee interactions}

The Planting for Pollinators (PfP) interfaces (illustrated in Figure 1) were created using a task-centred design approach [Lewis and Rieman, 1993], to target self-learning and decision-making by users when accessing the plant-bumblebee database in an interactive and user-friendly manner. The PfP user-interface contains a two-way filter, where any user selection (plant or bumblebee species) displays summary information for that selection in the middle panel (Figure 1a,b), while the panel on the opposite side is updated with the specific plants or bumblebees relevant for the selection made. For example, if the user has selected a bumblebee species in the left panel (shown in Figure 1a for the Buff-tailed bumblebee (Bombus terrestris), the plant species used as food plants by the selected bumblebee species are filtered from the database and shown in the panel on the right (most frequently used ones on the top), while ecological information for that bumblebee species is portrayed in the middle panel. Using this interface, the user can explore how different bumblebee species may have a preference for different flowering plants (for feeding on pollen and/or nectar - the sole food sources of bumblebees [Goulson, 2010] ) in addition to understanding possible reasons behind those preferences. Similarly, in a scenario where the user has an interest in a particular plant species (for example a wildflower, which may be considered a weed in the garden), they can look up which bumblebee species - if any - use this plant for feeding (Figure 1b). Alternatively, the user can use the list-based interface for exploring bumblebee-plant interactions in depth (Figure 1c) by either selecting a bumblebee species and getting a lists of top plants for the selected species or selecting a plant species and getting a list of bumblebee species that favour the selected plant. Through a calander-based interface (Figure 1d) users can also obtain personalised year-round planting recommendations for their gardens. Upon providing a list of plants already present in the garden, the system calls up a list of bumblebee species that are commonly seen on those plants (or the ten most frequently recorded bumblebee species if no plant species is selected).Then, the system provides a calender-based interface, recommending plants (with their flowering times) that can be planted to provide additional food sources for bumblebees by 'filling the gaps' where the plants selected by the user may not be flowering. Thus, using the above-described interfaces for 'information searches' 
may lead to decision-making and appreciation of existing garden (and other) plants as well as the considerable differences in food plant use among bumblebee species, which potentially could contribute to more wildlife-friendly garden management.

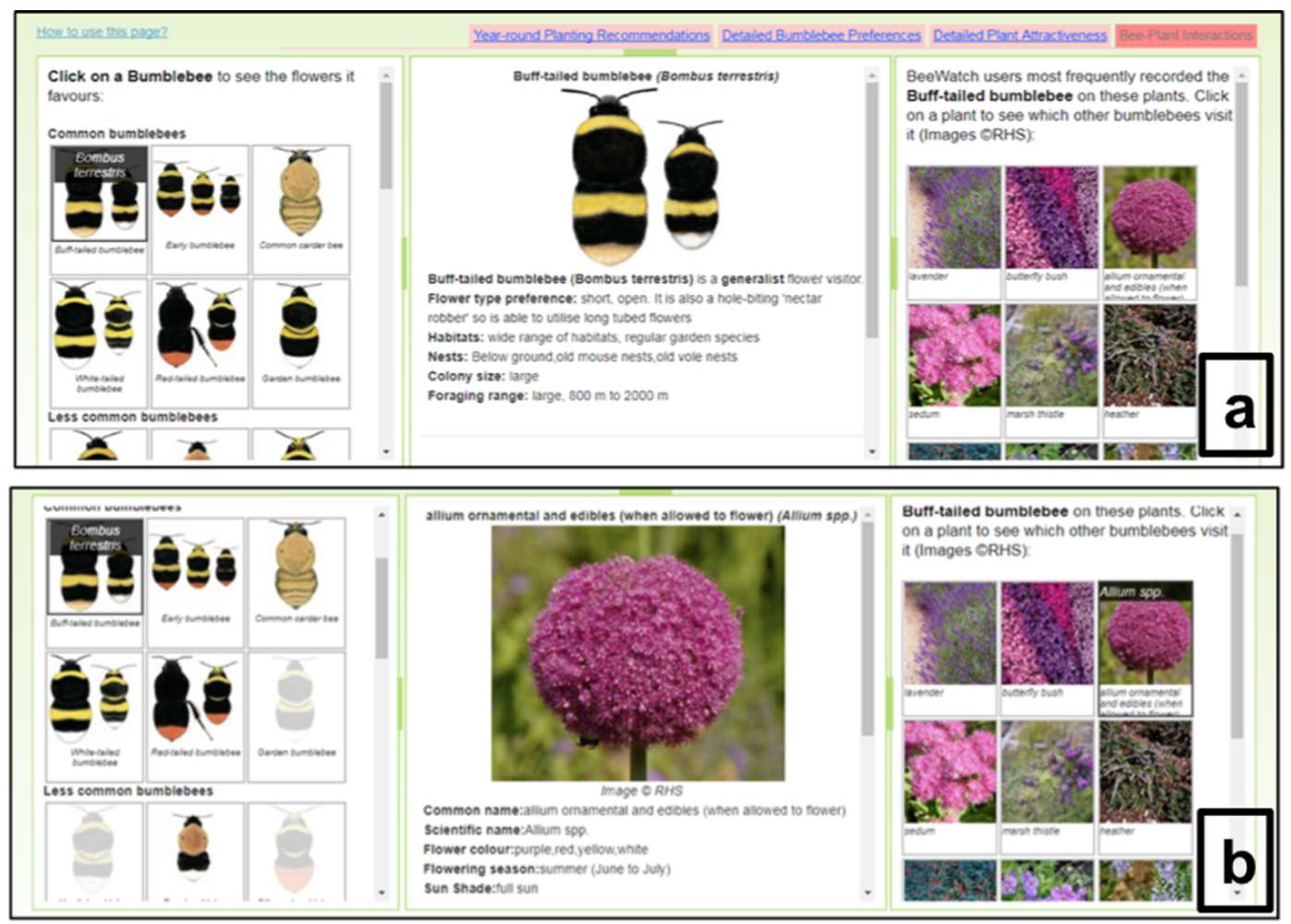

\begin{tabular}{|c|c|c|c|c|c|c|}
\hline \multicolumn{3}{|c|}{ Select a bumblebee species: } & \multicolumn{4}{|c|}{$\begin{array}{l}\text { Select a prant (you can also type some tetters to namow oownt } \\
\text { search): }\end{array}$} \\
\hline & & & \multicolumn{4}{|c|}{ Common comfrey (Symphytum officinale) } \\
\hline $\begin{array}{l}\text { Observed } \\
\text { in BeeWatch }\end{array}$ & $\begin{array}{l}\text { Predictions } \\
\text { from BeeWatch }\end{array}$ & $\begin{array}{l}\text { Predictions } \\
\text { from Literature }\end{array}$ & $\begin{array}{l}\text { Observed } \\
\text { in Literature }\end{array}$ & $\begin{array}{l}\text { Observed } \\
\text { in BeeWatch }\end{array}$ & $\begin{array}{l}\text { Predictions } \\
\text { from BeeWatch }\end{array}$ & \\
\hline Common Name & Scientific Name & $\begin{array}{l}\text { Number of } \\
\text { Observations }\end{array}$ & $\begin{array}{l}\text { Species } \\
\text { Common carder bee }\end{array}$ & & $\begin{array}{l}\text { Number of R } \\
53\end{array}$ & \\
\hline 1. lavender & Lavandula spp. & 168 & Earty bumblebee & & 53 & \\
\hline 2. butterfly bush & Buddleja spp. & 90 & $\begin{array}{l}\text { Soluthern cucroo but } \\
\text { Tree bumblebee }\end{array}$ & & $\begin{array}{l}30 \\
20\end{array}$ & \\
\hline 3. allium ornamental & I Allium spp. & 61 & $\begin{array}{l}\text { Bunf-talled bumbleber } \\
\text { Heath bumblebee }\end{array}$ & & $\begin{array}{l}19 \\
15\end{array}$ & \\
\hline
\end{tabular}

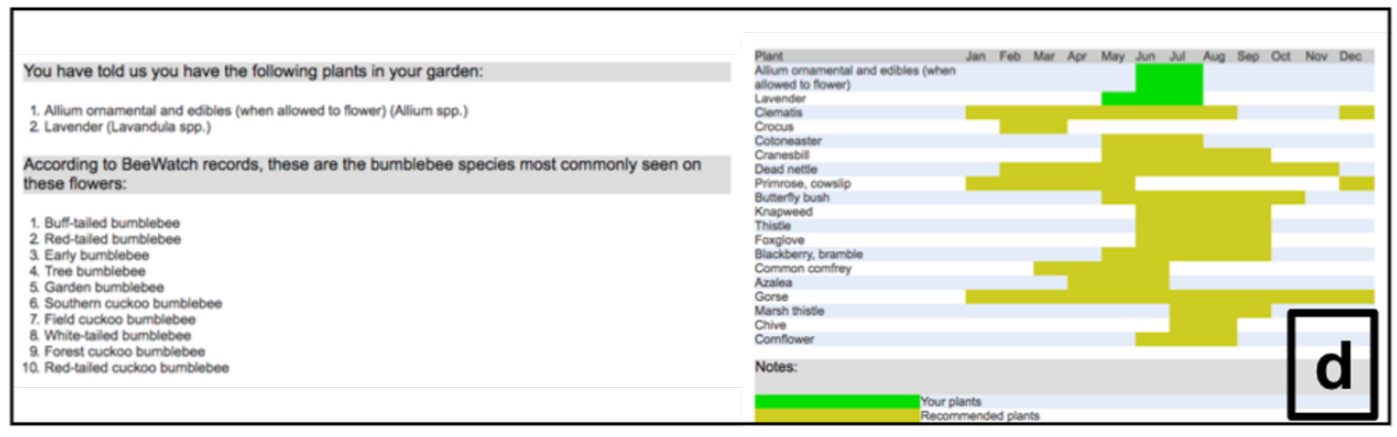

Figure 1. The Planting for Pollinators (PfP) landing page ( $\mathrm{a}, \mathrm{b})$ (http://www.abdn.ac.uk/ beewatch/planting). This interface has a two-way filter for exploring plant-bumblebee interactions. A bumblebee selection in (a) filters out the relevant plant species, shown at the right-hand side of the image while the plant selection in (b) filters out the relevant bumblebee species (showing species that are not connected to the selected plant in grey). Figure (c) shows the alternative list-based method for exploring bumblebee-plant interactions in depth, and (d) is an example of year-round planting recommendations generated for a specific query [see Wibowo et al., 2017, for details on the recommender system]. 


\subsubsection{Personalised planting advice using Natural Language Generation}

The second aspect of the Planting for Pollinators tool is continuous and longer-term engagement through embedding personalised planting advice in the current machine-generated feedback that the users receive when their submitted photograph is identified by BeeWatch (Figure 2) [van der Wal et al., 2016; Wibowo et al., 2017]. The first part of the new feedback (e.g. "According to data submitted by BeeWatch users, Early bumblebee is often seen on cranesbill (144 observations), cotoneaster (91) and lavender (84) ... ") highlights the top plants used by the bumblebee species identified in the user's submission, while acknowledging that the underlying dataset for this information is indeed user-generated. The second part of the feedback provides critically important 'ecological rules of thumb' (e.g. "...It is important to provide flowering plants throughout the season.") and a list of the top five food plants for this particular bumblebee species that might be flowering soon (e.g. "In the next month the plants used by Early bumblebees that are likely to be flowering are: cranesbill, cotoneaster, lavender, common comfrey and thyme..."). Again, this personalised feedback with pollinator-friendly advice may enable participants to take focussed and timely species-specific conservation action, whilst being provided with more generic guiding principles.

\subsection{Data collection}

The Planting for Pollinators tool and interactive interfaces embedded in the BeeWatch platform were assessed for three contexts, namely suitability for use during public outreach events, potential for use by gardeners and effectiveness as online tools for BeeWatch users across the U.K.. Each context offered the opportunity to create a spectrum of participants' interests and skills with respect to environmental issues, gardening, pollinators and biological recording. Using a concurrent mixed methods approach [Cresswell and Plano Clark, 2011], we obtained both quantitative and qualitative data, by capturing user behaviour on the website as well as users' perceptions through questionnaire surveys, individual interviews and focus groups (see for detail below). Such data provided us with a rich understanding of digital tool use in the context of environmental citizen science in the garden space. Specifically, the interface design-based element of the research provided the opportunity to capture novel features of participants' behaviours. Key themes were identified by an initial coding approach undertaken by the two first authors (SG and NS), followed by discussion and refinement amongst the members of the team, with each member holding a different disciplinary perspective and ontological orientation. Iterative use of quantitative analysis, and the category-based presentation thereof in diagrammatic and tabular format, helped uncover additional nuances in the data - thus meeting the criterion of exhaustiveness, while increasing reflexivity and enabling traceability amongst the team, thus striving for transparency in the analytical process [Nowell et al., 2017]. During the analysis, specific attention was paid to whether the new Planting for Pollinators interface embedded in BeeWatch supported changes in gardening experience and behaviour or identification expertise, or both. The analysis reported here follows a 'narration of engagement' to illustrate a multi-perspectival approach to citizens' participation in science through digital interaction in garden spaces. 
Thank you for joining BeeWatch. We hope you will find the experience interesting! One of our experts will verify your species identification and get back to you shortly. If you have correctly identified your photo, this would be the first record to BeeWatch of a Red-tailed bumblebee in this $10 \mathrm{~km}$ square since August 2016. The Red-tailed bumblebee is a common species in Britain. Nest-searching queens can be seen from March to June, workers present from April onwards, and males and new females from July to early October. Its range is expanding northwards in north-east Scotland and the Highlands. For a national distribution map: see: http://data.nbn.org.uk/Taxa/NHMSYS0000875490.

Thank you for submitting this photo. You have correctly identified the bumblebee as a Buff-tailed bumblebee.

Planting Advice

According to data submitted by BeeWatch users, Buff-tailed bumblebee is often seen on lavender (168 observations), butterfly bush (90), allium (61), sedum (55) and marsh thistle (49). It is important to provide flowering plants throughout the season. In the next month the plants used by Buff-tailed bumblebees that are likely to be flowering are: lavender, butterfly bush and allium (ornamental and edibles) when allowed to flower. For more information and planting advice, please go to our new and interactive page Planting for Pollinators (www.abdn.ac.uk/beewatch).

\section{Identification Advice}

As you are already aware queens and males of this species have a buff coloured tail. Workers have a white tail, which makes it difficult to separate them from White-tailed bumblebees. A narrow fringe of buff-coloured hairs at the top margin of the tail, when seen, can identify Buff-tailed workers. The two yellow bands are golden in this species and more of a lemon-yellow in the White-tailed bumblebee.

\section{UK Status and Distribution}

The Buff-tailed bumblebee is common and widespread across most of the UK, although its range has only recently expanded into the Highlands. For a national distribution map see:

https://species.nbnatlas.org/species/NHMSYS0000875475

\section{Habitat}

The Buff-tailed bumblebee is found in most habitats, and is frequent in gardens. It is a generalist flower visitor for both pollen and nectar and, although short-tongued, it can utilise long-tubed flowers by cutting a hole in the flower to reach the nectar.

\section{Flight season}

The queen of the Buff-tailed bumblebee can be seen from February to April, whilst the males can be found from July to October.

Interestingly, in the south of the UK active nests have been found during the winter months.

Figure 2. Computer-generated feedback sent to BeeWatch users. A) is an example of automatically generated text sent to the user by email as an online submission has been made, to thank the participant, contextualise the submission (in terms of potential value of the record in biological recording terms) and offer associated ecological information that may foster learning and interest. B) is an example of Natural Language Generated (NLG) planting advice (red text) embedded in the existing NLG feedback sent to BeeWatch users after (expert or crowd-based) verification had taken place. See Blake et al. [2012] for details on the NLG system and van der Wal et al. [2016] for an evaluation thereof.

\subsubsection{Interviews with outreach officers}

The Planting for Pollinators interfaces were used during 15 engagement events with members of the public in March and April 2017 across England (Plymouth, Nottingham, York, Newcastle), Wales (Flintshire) and Scotland (Glasgow, Forfar, Perth, Aberdeen); they were held at garden centres, formal gardens, science fairs, biological recording forums, a fabric retail outlet and during two community events, and engaged more than 1,500 members of the public in reasonable to considerable depth. In addition to the digital tools, the engagement materials 
included project postcards ( $>5,000$ disseminated - see appendix A), a voting activity where members of the public were asked how they would spend money to address threats affecting bumblebees, a quiz of plant images to guess which were good for pollinators, and cards with a range of positive actions for people to consider. The outreach officers (5 in total, named 'P1-P5' in the results section) who managed these events were interviewed (semi-structured, audio recorded with permission, average duration $31 \mathrm{mins}$, range 20-39 $\mathrm{min}$ ), and the audio data was subsequently transcribed verbatim for analysis. The interviews focussed on two key aspects: first, the effectiveness of using the Planting for Pollinators interfaces within the context of the above outlined setup for public engagement; and second, the outreach officers' own perceptions as 'potential users' with an interest in pollinator-friendly gardening.

\subsubsection{Focus groups with gardeners}

There were three (G1-G3) focus groups in total. G1 (2 members) was comprised of professional (university) gardeners who had a rich understanding of issues surrounding garden management for specific purposes (e.g. medicinal trail, native plants trail). G2 (5 members) brought together people with an interest in wildlife gardening and included four volunteers working towards a John Muir award, ${ }^{1}$ and the council staff member supporting their community learning. G3 (4 members) consisted of volunteers and staff from the university with less experience in gardening but interested in learning about pollinator-friendly gardening. The three groups were thus comprised of people with different backgrounds, motivations for and knowledge of gardening, and expectations of what constituted wildlife-friendly gardening. The main objective of the focus groups was to gain in-depth understanding of how a potential target user base of the Planting for Pollinators interfaces might use the tools for making gardening decisions. Each focus group was therefore composed of three parts: 1) a discussion on information sources used to support gardening-related activities; 2) an interactive session with a demonstration of all three PfP interfaces; and 3) a reflection on the interfaces as a potential information source for current gardening activities. All the focus groups were recorded (duration 54, 65 and 70 minutes long respectively) and field notes were taken. The audios were then transcribed verbatim for subsequent analysis.

\subsubsection{BeeWatch web engagement, questionnaire and follow-up interviews}

Google analytics revealed that between 1 April 2017 - a day after the Planting for Pollinators pages opened for U.K.-wide use - and 29 March 2018, a total of 5,080 (different) users visited the BeeWatch website, adding up to a total of 8,064 sessions. The average duration of a session ( 5 minutes and 14 seconds) and the average time spent on a page ( 1 minute and 11 seconds) were considerable. A total of 2,324 unique page views were observed for the Planting for Pollinators landing page, with an average engagement time of 2 minutes and 12 seconds.

A questionnaire was developed to assess the real-world usage and impact of BeeWatch and its associated features, which included the Planting for Pollinators

\footnotetext{
${ }^{1}$ https: / / www.johnmuirtrust.org/john-muir-award: this award involves discovering, exploring and conserving a wildlife place and sharing experiences.
} 
interactive interfaces (Figure 1) and Natural Language Generated feedback with planting advice (Figure 2), in terms of their effectiveness for attitudinal and behaviour change. The questionnaire (appendix B) was divided into four main sections: section 1 to capture background information on users' garden (size and type), gardening behaviour (main uses and time spent gardening) and BeeWatch participation (year of joining, method of recruitment, frequency of use, features used and participation in similar initiatives); section 2 to reveal user motivations for BeeWatch participation and use of specific features including PfP; section 3 to identify any behavioural or attitudinal change due to participation; and section 4 to obtain demographic information, and to invite participants for a follow-up phone interview. BeeWatch users were sent the questionnaire $(n=624)$ via email (on 4 July 2017, reminder after 4 weeks), contacting only those who had received tailored planting advice. A total of 155 responses (25\% response rate) were received, of which 131 answered all questions. Almost all (21 out of 24) who did not complete stopped answering questions regarding motivations for participation in BeeWatch (in section 2, which were mostly open-ended), while 3 respondents left when reaching questions concerning knowledge and attitude change (section 3 ).

Gender distribution of our respondents was relatively equal ( $55 \%$ female), but almost three quarters were $>50$ years of age. Annual household income distribution was rather broad, with $27 \%$ reporting $<£ 25000,23 \% £ 25,000-£ 35,000$, $19 \% £ 35,000-£ 50,000$, and $30.3 \%<£ 50,000$, suggesting that participants with different economic backgrounds were involved in the project. The median area dedicated for gardening was reported as $222 \mathrm{~m}^{2}$ (ranging from 0 (no garden) to $141,640 \mathrm{~m}^{2}$. Most respondents owned a private garden (93\%), while those who did not reported access to an allotment, shared garden, communal garden or tenement. A relatively small number of respondents $(23 \%)$ noted that they were also involved in (one or more) other conservation initiatives, suggesting that most participants were not regularly involved in large-scale, organised forms of 'conservation'.

A small number of users $(n=11)$ gave their consent and contact details for a follow-up telephone interview, and those were called over the course of two weeks. Interviewees were again from a broad range of demographics (e.g. 23-61 years of age) and with a variety of economic backgrounds. Interviews lasted on average 8 minutes and 34 seconds, and each interview was recorded and transcribed verbatim with the interviewee's consent. Coding was then used to identify key themes within both the survey responses and the transcribed interviews.

When coding the survey data, it became apparent that the determining factor in producing an explicit environmental perception and/or gardening behaviour change was dependent on whether participants had a significant amount of local ecological knowledge before engaging with BeeWatch. Thus, we designated two distinct participant categories: less-knowledgeable participants and knowledgeable participants. Whether a participant was deemed 'knowledgeable' or 'less-knowledgeable' was determined by evidence given by the participant of local ecological knowledge in any of their responses. For example, one participant mentioned being a countryside ranger, and another mentioned being a natural sciences faculty member of a university. Evidence was, however, most often found in response to section 3 of the questionnaire, where participants gave evidence as to why they felt BeeWatch had not resulted in a gardening behaviour/environmental perception change with statements such as "No... I've always been interested in the 
environment" and "We have always been conscious of how the shore land has been managed. I have been adding bee-friendly shrubs/plants over the years ... BeeWatch just enhanced this." A third category was created to identify those participants who were biological recorders (i.e. having a species recording interest and associated skill level). In many cases we could use the response given to the question "Are you involved in any other conservation initiatives aside from BeeWatch?". However, evidence came also from free text in response to other questionnaire items. Part of those identified as biological recorder appeared solely bee focussed (or even bumblebees only, including 9 participating in BeeWalk - a field-based programme that requires a reasonable level of bumblebee identification skills), but the majority recorded species more widely (with the RSPB and BTO garden birdwatch being mentioned repeatedly). Although some individuals were evidently highly skilled (a plant county recorder, several insect experts), most appeared naturalists who enjoyed being outside and identify species around them without clearly being highly skilled.

\section{Results}

\subsection{Interviews with outreach officers}

\subsubsection{Accessibility}

Interviewees (P1-P5) found the species group (bumblebees) and the activity (gardening) to be important aspects for engaging the general public as people found them familiar, memorable and relatable to their personal experiences: “... Everyone has a bumblebee story [...] you have been stung by one or used to chase one $[\ldots]$ it's so easy to relate to..." (P4); and "... allowed to engage [...] and people were interested as this was something that they could do in their back gardens[...] local village [...] on a much more individual scale as well as the bigger scale..."(P2). Perhaps unsurprisingly, the use of technology for engagement uncovered some contrasts with older people, who were generally less interested in technology ("...getting them to even look at the tablet was pretty challenging [...] people just wanted to go and get a cup of coffee in the cafe and then buy their pansies..."(P1), while younger people seemed more willing to engage with the online tools ("...up to an hour and a few of them were quite young people who were showing interest..."(P4). So, at this first level of analysis we identify some new users: young people who may not commonly be involved with gardening. Problems related to lack of internet access, insufficient bandwidth and setting up computers such that they could be used well were also mentioned, and indeed identified by outreach officers as a potential limitation of digital technologies for engagement in general.

\subsubsection{Quality of experiences}

With respect to the quality of the experience that the tools provided for different users, we noted that the interfaces allowed for 'active sharing of knowledge' related to people's experiences in their gardens. It was clear that the underlying information of Planting for Pollinators was deemed superior to that of other lists: "...people tend to get quite frustrated when they feel they've got a garden full of plants that are great for pollinators but they just [...] they aren't on that list, whereas the planting for pollinators tool on the website has got a much broader list..."(P3). Outreach officers also observed appreciation that the planting information was user-generated, which P4 highlighted could also be perceived as a motivator for people to further contribute 
to the underlying database: "...people would see it as an organic tool [...] it's something that they can contribute to [...] its tapping into that whole idea of what citizen science is all about [...] sharing information [...] that bees are landing on plants in my garden... "(P4). More importantly, it was argued that the BeeWatch platform in general enabled more meaningful and engaging user experiences due to its focus on personalisation and provision of suitable feedback in comparison with similar projects: "...people like talking about their own garden and their own space, and the fact that they can kind of input that quite personal information and get this personal profile back will be very popular [...] whereas a lot of the kind of leaflets and booklets and guides that you give out that make recommendations for improving for pollinators, obviously they aren't tailored at all..."(P3); and "...just submitting a photograph and it going into the ether and them never hearing anything again..."(P3).

Key to the success of Planting for Pollinators, and the static representation thereof in the form of a postcard (appendix A) handed out during all outreach events and studied in detail by many, was that people were informed that there were more than just one or a few species of bumblebees; that several of the common ones could be recognised by lay people; and that these different bumblebee species were attracted to different plant species and hence could be catered for: "...the information... you know the postcards? That's what I ended up giving most people and again that principle of saying well these are the plant species that these different bumble bee species favour... people really liked that idea, and people were really engaged by that kind of, did you know there are lots of different species of bumblebee? And they have different requirements..."(P1).

Thus, the interviews with the outreach officers appears to point towards an ability of the focal citizen science initiative with its digital tools to penetrate the realm of action across potentially different social contexts.

\subsection{Focus groups with gardeners}

\subsubsection{Specificity of information and personal awareness}

Online sources of gardening information, including those provided by the Royal Horticultural Society (R.H.S.) and the Bumblebee Conservation Trust, were perceived as timely and up-to-date, but complementary to word of mouth (including speaking with experienced beekeepers) and more static physical sources (such as books, periodicals, magazines, and R.H.S. bee-friendly labels). All groups highlighted a lack of awareness around specificity of foraging preferences of different species (". . you almost ignore the bumblebees in a sense, you see them buzzing around, you don't realise that there are all these different types that do certain things with certain plants..."(G1)), and exhibited enthusiasm to use this information for making gardening decisions based on the presented information: "... I should have looked at this at more depth before planting those..."(G2).

\subsubsection{Variability of formats to bridge knowledge with different experiences}

In terms of user-interactions with the information, the more experienced gardeners preferred the text-based plant lists, while the less experienced found them difficult to navigate compared to the image-based two-way filtering for exploring 
species-species interactions: "... that's the problem with this if you haven't got any pictures [...] you don't know the name of it [...] you just know how it looks..." (G2); and "...that's pretty good [...] obviously for people who find the bees and want to know what they can do to help them, but then you find the plants. That's really smart..."(G3).

Two of the groups explicitly mentioned that the uptake of this information would definitely increase if it was available as a mobile application: ". . if it is in my pocket then it's easy..." (G3); though a participant of G2, who had previously shown scepticism towards 'promoting technology', mentioned that paper versions should also be made available for people who do not have access to a computer or a smartphone.

\subsection{Questionnaire}

\subsubsection{BeeWatch participation}

The majority of questionnaire respondents $(72 \%)$ were new users (joined in the last 2 years, i.e. 2016/2017), while 18\% had been users for 3-4 years; the remaining $9 \%$ were users for more than 4 years, pointing to considerable turnover. Means of recruitment revealed that more than half of the respondents $(54 \%)$ found BeeWatch through an internet search, highlighting the ability of the project to recruit organically and without much marketing effort. The next source of user recruitment $(17 \%)$ was from the partner organisation website (Bumblebee Conservation Trust), while another $15 \%$ found the programme through physical means (such as flyers, books, friends and family, or a physical outreach event). Only 3\% found BeeWatch through social media (as expected, since the project has only had a presence on the popular social media website Facebook since September 2017).

\subsection{Interviews with BeeWatch users}

\subsubsection{Impact on actions: aesthetic and affective shifts}

Follow-up interviews served to verify the findings from the questionnaire and obtain more extensive information on how users may or may not have changed how they viewed, managed and understood their garden areas (as a result of using BeeWatch). Data was based on how they spoke about this in conversation, rather than as responses to direct questions which they could take the time to write and edit a response to.

As was the case for questionnaire respondents, for most interviewees this was also their first experience of participating in an environmental conservation initiative. The interviews confirmed that by engaging with bumblebees and their relationships with food sources, users began to change the ways they interacted with other non-pollinator species they encountered. As one user stated: "Now I'm thinking whenever I mow the lawn, 'Oh I had better not cut those dandelions!' [...] It does look a bit messy but I do think it is nicer that way now [...] I also left the mushrooms growing on the old tree trunk this year, it just sort of made me think, you know, why DO I always get rid of them?". Another user explained how BeeWatch had made them more attuned to the life in their garden, when one evening they were hesitant to open their backdoor, as a sparrow was feeding nearby: "I thought, if I open the door 
now, I'm going to scare him off! And what he's eating, that's, you know, that's his dinner isn't it? [...] so I waited until he was done." These affective encounters [Archambault, 2016] with wildlife through participation in BeeWatch display that citizen science projects can successfully harness ways of knowing that are embodied, and thus part of felt experience. Here we begin to see a sense of 'response-ability'

[D. Haraway, 2016], that is, the ability to feel and act in ways that are responsive and in relation to the environments which people inhabit.

\subsection{Questionnaire and Interview Findings}

Data analysis revealed different main motivational starting points which appeared to unfold along two overlapping axes, namely that of 'learning' and 'helping' (Figure 3). Helping took several forms, with a small number of survey participants (7\%) wanting to 'help others with species identification through crowdsourcing'; this was primarily declared as motivation for BeeWatch by people who recently learned such skills through participation in the programme. A much more widespread motivation to take part was 'helping bees in ones' garden' $(30 \%)$, and typically concerned knowledge acquisition for a specific purpose (e.g. "To find out helpful plants to put in my garden"). Yet others stressed the importance of helping bumblebees beyond one's own garden, i.e. 'helping conservation (of bees)' more generally (34\%). This regularly overlapped with a desire "To make a contribution to the research needed to aid bumblebee conservation." Surprisingly, making a science contribution - identified as one of the primary motivators of online citizen science projects [Raddick et al., 2013] - was key to only 30\% of our respondents, and only part of them explicitly mentioned data-related dimensions (e.g. recording, monitoring, species distribution, gathering of data, knowledge production), rather than relatively unspecific references such as 'helping science' or 'helping BeeWatch'. This raises important questions including why BeeWatch users may not perceive themselves first and foremost as 'contributors' to a citizen science programme, but instead view the project primarily as a learning platform - to gain access to knowledge about, as well as a means to support, their natural environment. 'Acquiring or improving bumblebee identification skills' was key to most participants (82\%), often starting off as 'to find out which species are in our garden". 'Broader learning', i.e. curiosity or a particular personal interest', not necessarily linked to a scientific or social purpose or a cause (i.e. "interest in natural history"), but also the requesting of a species identification without an indication to want to learn such a skill, was a recognisable motivation for $38 \%$ of participants. The practical reason for the predominance of 'learning' may be associated with the different 'learning-related features' on BeeWatch, such as personalised identification feedback, training material and more recently personalised action information to its users. However, how these 'features' enable users to perceive the project as primarily a learning platform may be revealed through the behaviour and attitude changes reported by the BeeWatch users (Figure 4, appendix D). Through codifying the survey data and interviews, we identified three distinct user groups: knowledgeable users, less-knowledgeable users and users with a biological recording interest, with their responses outlined below. 


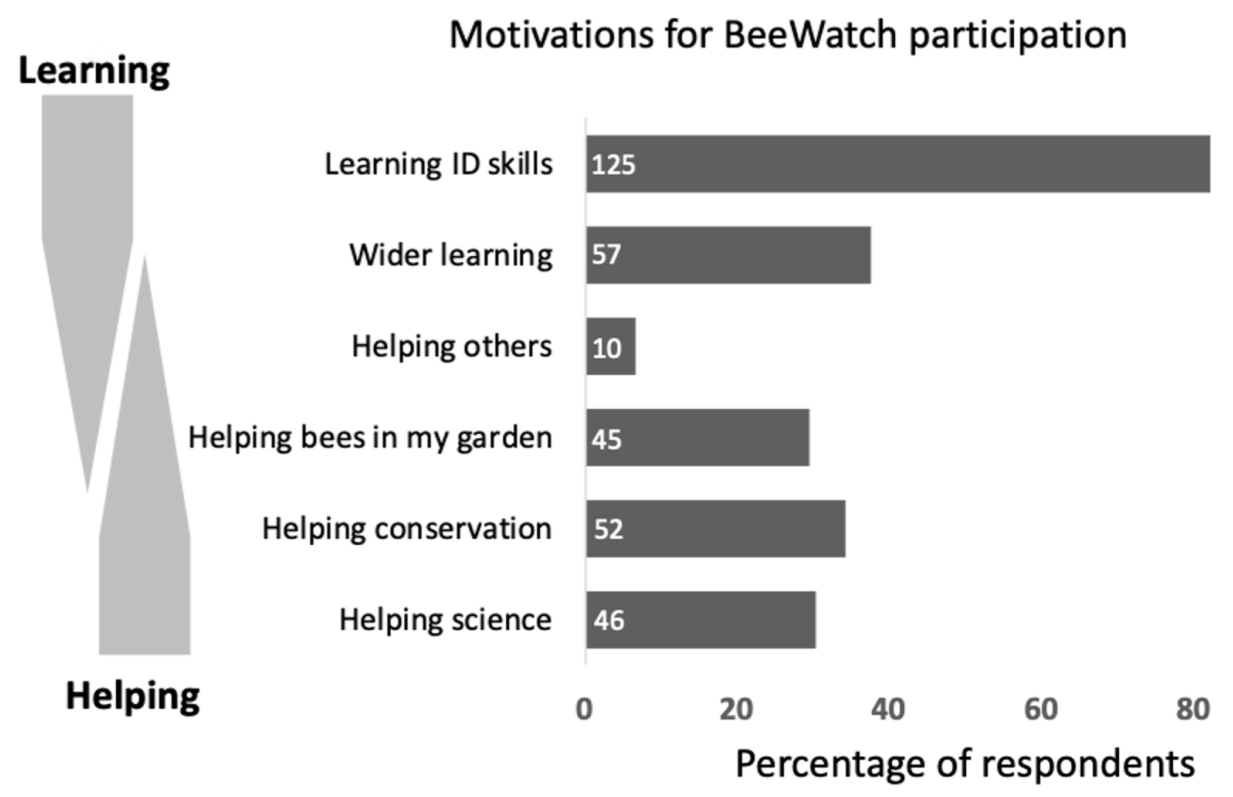

Figure 3. Motivations for participation on BeeWatch, based on questionnaire responses. Multiple motivations could be given by participants $(n=152)$, hence percentages add up to more than 100.

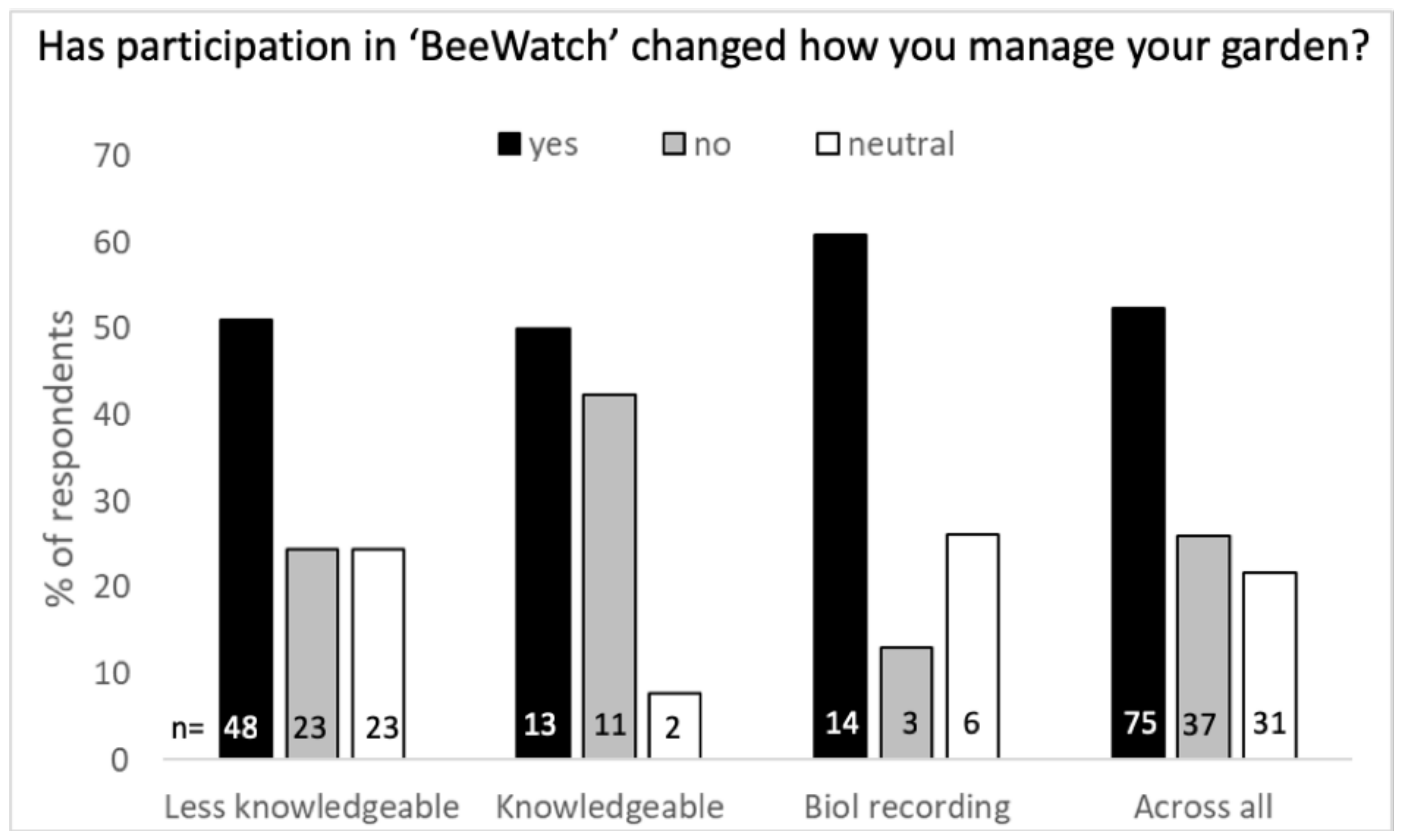

Figure 4. Distribution of questionnaire respondents $(n=143)$ with respect to the influence of BeeWatch on the management of their garden area, for the three identified groupings (knowledgeable, less-knowledgeable, biological recorder participants) and the groupings combined.

\subsubsection{Less-knowledgeable users}

The majority of respondents showed little to no evidence of having knowledge about their local wildlife and the broader environment prior to engaging with the project $(n=94)$. This group of users was overwhelmingly motivated by an interest to learn more about bumblebees, with numerous statements demonstrating affection 
(e.g. "I love bumblebees") - a strong motivator also for other citizen science initiatives [Domroese and Johnson, 2017]. Most cited identification skills as a motivating factor $(n=72)$. Use varied between yearly $(n=41)$, monthly $(n=32)$ and weekly $(n=4)$. Changes to gardening behaviour and associated environmental understanding were reported by just over half of this group $(51 \%, n=48,23$ declaring no change; Figure 4, appendix D), which consisted of: planting more pollinator-friendly plants, leaving unmown areas of grass and weeds to grow, reducing or no longer using pesticides, placing or building bee homes to encourage nesting, planting flowering plants in succession to ensure a year-round supply of pollinator food, leaving out plates of sugared water for tired bees, and avoiding disturbing bumblebee nests and the areas around them. Initiatives such as BeeWatch can therefore be understood to have a significant impact on the least experienced of users.

\subsubsection{Knowledgeable users}

A smaller portion of users $(n=26)$ showed evidence of having a considerable amount of knowledge about their local wildlife and the broader environment prior to engaging with BeeWatch. This group was also primarily motivated by a desire to learn more about bumblebees, with several explicitly stating that this was a result of their affection for bees. Yet more had an interest in species identification $(n=23)$ compared to the less-knowledgeable group, with the majority using the platform on a monthly basis $(n=11)$. Behaviour and perception changes as a result of BeeWatch were also quite significant with this group, and although half of the users stated there had been a change $(50 \%, n=13)$, a much greater proportion of users indicated this had not been the case $(n=11$; Figure 4$)$. Gardening changes consisted of planting more pollinator-friendly plants, planting in succession, leaving areas of grass unmown, encouraging weeds and the cessation of pesticide use. Importantly, those who stated that BeeWatch had not had an impact on their gardening practices or of their understanding of the environment more broadly overwhelmingly mentioned that this was due to already being aware of the types of gardening actions they could take to assist pollinators, with several respondents stating that BeeWatch had nevertheless helped reinforce their understanding $(n=10)$.

\subsubsection{Users with a biological recording interest}

A total of 23 users were identified as having a strong biological recording background, evidenced through their responses and the other recording initiatives that they had stated their involvement in. The primary motivation for this group was to improve their identification skills $(n=23$, i.e. all) and get feedback on their submissions, though learning about bumblebees was also widely cited. The majority of these participants used the platform on a yearly basis $(n=10)$, with the greatest proportion of all three user categories reporting behavioural change $(61 \%$, $\mathrm{n}=14$ ). Changes to their gardening behaviour, however, were consolidatory and not as far-reaching as for the other two user groups as practises were often already environmentally friendly. 
BeeWatch provided participants with a platform to learn widely about a popular species group, while encouraging participants to spend time in close-contact with them. To collect an appropriate photo for submission to BeeWatch, the user must often take multiple photos of a single bumblebee, and in close enough proximity as to make its taxonomic features discernible, such as different coloured bands around its body, pollen baskets on its legs, facial hair colour, and even the type of plant it is feeding from. Poised over a flower patch with the camera almost touching the bee, an inexperienced user may hurry away in terror as the insect buzzes loudly past their ear as it takes flight in search of another flower. This is a rather incongruous match between close observation and developing positive attitudes towards non-human life. Yet, multiple respondents noted how they were "petrified of bees but find them beautiful and want to make sure they are protected", with a more experienced user stating "I have learned lots about bees, male and female, how to identify. Before, I would just see a bee, now I can tell different kinds of bees, also now telling my husband and children, who are now interested. I used to be afraid of bees, so it's pretty amazing really." So, it seems that through continuous exposure, trust may be slowly developed between human and bee, photographing without fear of being stung, creating attachments based on affect [D. Haraway, 2016].

Particularly for the less knowledgeable users, it appears that BeeWatch has, very much unintentionally, put participants into positions where they were able to form relationships with non-humans. Surprisingly, the identification task appeared to play an equal role to the more general interest in finding out more about bees and plants. Arguably, it is this multi-species interaction that generates a new type of phenomenological and hybrid scientific knowledge. In analysing the changing ecological landscape of current times, the philosopher Donna D. Haraway [2016] argues that a new way of being is required, which is 'sym-poiesis', or making-with, rather than auto-poiesis, or self-making. Such 'making with' involves one personally and brings one together with others through ongoing, material and affective exchanges. One could argue that for the less experienced users the possibility offered by Beewatch to participate in the work of science and conservation, and being exposed to the interactivity of the platform and its multiple features, supported an existing motivation 'to help the bees'. Data captured other, equally interesting aspects of the human-non-human relation. The garden is a place where people "walk a lot slower and look closer at the surrounding vegetation", in a way that enhances one's perception and sense of well-being [Gray and Colucci-Gray, 2018]. As one user happily explained: "It has generated an interest in insects as a whole that I had as a child but lost along the way. I now enjoy wasting time watching them at work once again (and no one to tell me to stop doing it)".

This inter-species affect was cultivated through a number of pathways. Learning the names of different species was the most common first stage, with users commenting how they "used to not even know the difference between bees and wasps! [but now...] can identify loads of different types of bee..." forming the beginning of a recognition that the insects flying around in their gardens were not simply obnoxious or scary stinging objects. Learning to identify even one type of bumblebee requires one to examine multiple parts of their taxonomy, which provided users a way into learning more about their behaviour, such as how bumblebees are integral to the survival of certain plants in their gardens, how the length of their tongue influences what types of flowers they can feed from, or how the presence of pollen baskets on the legs of some bees allows them to carry pollen 
back to their nests. As they learned how different species have different (feeding, nesting and other) preferences - and witnessed this behaviour in their own gardens - participants began to recognise bumblebees as moving with intent through their environment; they were no longer understood to be mindlessly buzzing around, but recognised as having specific motivations, preferences and desires. This was often accompanied by participants describing what they understood the insects' emotive responses to be ("They absolutely go mad for our lavender, it's the whole reason we got it."; "... they're really quite gentle once you get used to them... "; "... I put a bee house out but they didn't seem to like it very much").

The results from the more experienced gardeners revealed that the number of people who either did or did not change their gardening practices was comparable. This suggest that the information provided agency for some and yet for others perhaps did not exceed what they already knew. For those who displayed biological recording interest the platform may have appeared almost naturally aligned, leading to a proportionally large change in gardening practices. Such changes were primarily a consolidation of otherwise environmentally-friendly approaches (e.g. "I let the grass grow longer to encourage heather"). Or, as more casual gardener noted: "I actually see my garden as a place for the creatures in it, rather than a place for me, as I already have my house. It doesn't bother me that it might look a bit untidy, I love to see all the creatures coming to it and being able to feed and live there".

It is through cultivating a fascination with identification that BeeWatch creates a space where scientific and non-scientific knowledge can co-exist and reinforce one another, an occurrence which has been elegantly demonstrated elsewhere through the study of expert ecologists [Ellis, 2011]. We observed this in people during outreach events and focus groups, and in BeeWatch users from their questionnaire responses and during follow-up interviews. Providing people with the basic insight that there are different species of bumblebees, giving them access to tools to distinguish between them [see also van der Wal et al., 2016], and communicating the basic understanding - through 'Planting for Pollinators' (Figure 1) - that different bumblebee species use different food plants, kindled or heightened (depending on their knowledge level) a desire to explore what these different species are up to, and how to assist them through positive gardening action. This approach is reminiscent of Isabelle Stengers' call for a shift in practice towards a 'Slow Science' [Stengers, 2018], wherein she suggests that co-production of knowledge between scientists and broader publics - whilst appearing to reduce productivity, instead produces something of high meaning and value to a broad range of individuals.

Conclusion

Interactive digital tools which invite and utilise the knowledge and experience of a variety of users operating in their immediate surroundings have the potential to engender positive action for species conservation. Most platforms designed to collect data for citizen science purposes focus on a single species or group in order to make the project accessible. In this case, the focus on a charismatic species group such as bumblebees is a productive way to engage large groups of people with little to no previous environmental or ecological knowledge [Lorimer, 2007]. While this runs the risk of species prioritisation and obscuring the broader ecological processes that are contributing to species decline, we believe that BeeWatch has successfully gone beyond a single charismatic, politicised species. In order to help 
bumblebees, participants formed relationships with other species such as weeds, grasses and flowers, thus creating attachments to the life-worlds of these species, and cultivating a non-dualistic understanding of nature. We outline three key aspects for replicating the success of this initiative in other contexts, and with other species: 1) a focus on the local interdependence of species, 2) their attraction to quotidian and widely-accessible sites of ecological activity, and 3) close human interaction with observable species. We believe that these three aspects can be reproduced in other contexts, and can, in combination, further help to develop valuable attachments that see humans embedded-within rather than separated-from the natural world, a key challenge that must be overcome to avoid further large-scale biodiversity loss.

\section{Appendix A. Planting for Pollinators postcard}
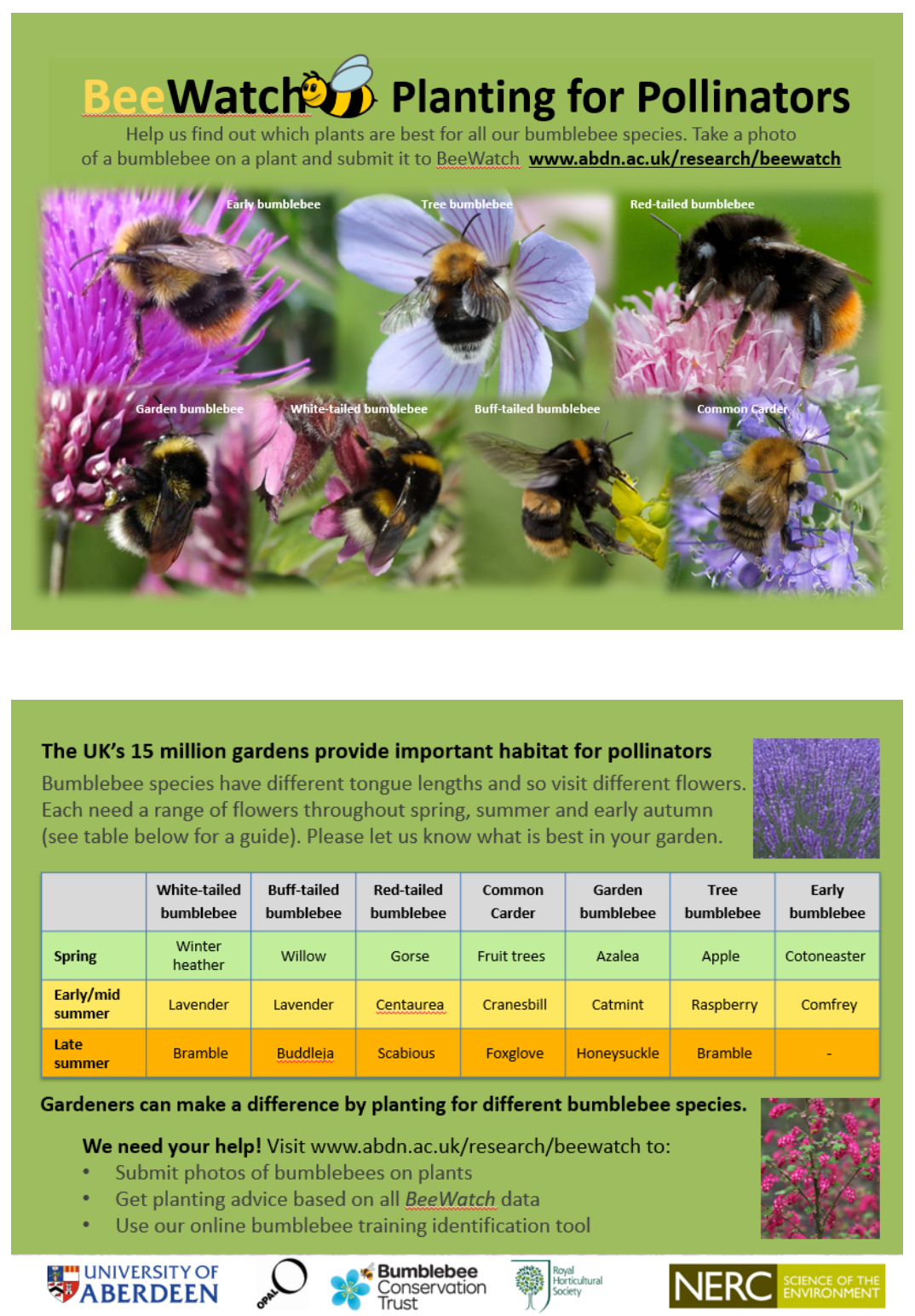

Figure 5. Planting for Pollinators postcard (front and back), handed out during the 15 public engagement sessions across the U.K., showing the top seven most common bumblebees (front) and selected species-specific planting advice on the back. 
Appendix B.

Questionnaire used in the study

\section{Section 1: Basic User Information}

1 How much land (a very rough estimate) do you have dedicated to gardening in square metres? This can include pathways, balconies, paved areas with pots, etc. anywhere where you have things growing.

2 Is it a privately owned or communal garden area?

3 What do you use the garden for?

4 How many hours per week is spent maintaining your garden area (by yourself or others)?

5 Are you involved in any other conservation initiatives aside from BeeWatch?

6 When did you start using BeeWatch?

7 How did you find out about BeeWatch?

8 What is your main reason for participation?

9 How often do you use BeeWatch?

10 Which of the following features of the site do you use or have used in the past?

\section{Section 2: Understanding User Motivations}

11 Please describe briefly your motivations for submitting photos of bumblebees to BeeWatch (if relevant).

12 Please describe briefly your motivation to identify photos submitted by other BeeWatch users (if relevant).

13 Please describe your motivation for using the training tool (if relevant).

14 Please describe briefly your motivation for using planting for pollinators tool (if relevant).

15 Do you find the feedback that you get on submission of your records as shown in the example below useful/Not useful? Please explain. [See Figure 2 a for example feedback].

16 Do you find the email feedback that you get on verification of your record(s) as shown in the example below useful/Not useful? Please explain which specific elements you did or did not find useful. [See Figure $2 b$ for example feedback].

\section{Section 3: Environmental Interactions}

17 If you document bumblebee sightings, please list the types of places you do this. Which place is the most frequent?

18 Has taking part in BeeWatch changed how you see your garden area? Please explain. 
19 Has BeeWatch led to any changes in how you manage your garden area? If so, what changes?

20 Are there any specific parts or features of BeeWatch that have influenced this?

21 Have you noticed any differences (in your garden area) as a result?

22 Do you see the changes to your garden area as positive, negative, or neutral? And why?

23 Do you feel you have learned any new skills or gained any new knowledge from using BeeWatch? Please describe.

24 How do you feel using BeeWatch has changed your relationship with the wider environment, if at all?

25 Can you describe any examples of how?

\section{Section 4: Demographic Information}

26 Age bracket.

27 Gender.

28 Annual household income (approximately).

29 Approximate location of home (first half of postcode).

30 If you are willing to participate in a brief follow-up call in 2-3 weeks' time in order to help us gain a deeper understanding of our project, please provide a contact number below.

31 Also, if you are willing to be identifiable to us, please leave your email (so that we can interpret your answers in the context of your BeeWatch activity). 
Appendix C.

Background

information of

BeeWatch users

based on

questionnaire data
A

Time spent gardening per week

Frequency of using BeeWatch

Prior level of ecological knowledge

Prior level of biological recording

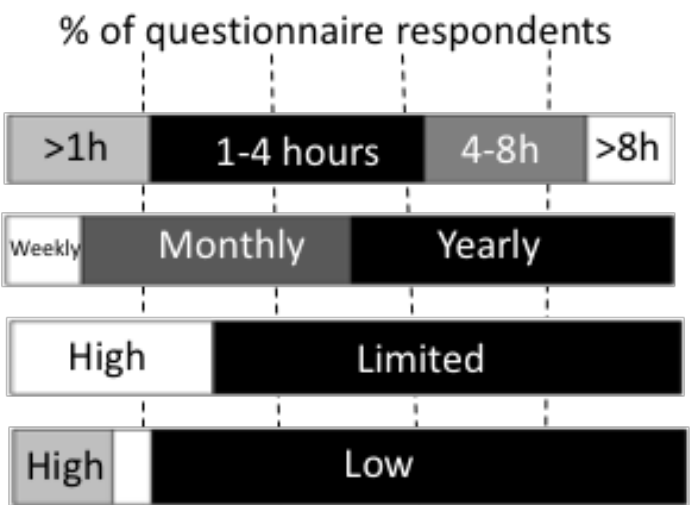

B

Figure 6. Background information of BeeWatch users based on questionnaire data. A) Graphical summary of the distribution of respondents in our sample $(n=155)$ in terms of 'time spent gardening' (question 4 in appendix A) and 'frequency of BeeWatch use' (question 9). Prior level of ecological knowledge and biological recording were extracted from textual responses across all questionnaire items. B) Word cloud analysis of the question 3: what do you use the garden for? The larger font size, the greater the occurrence of the word. Largest font sizes, such as Growing, Vegetables and Fruit, have more than 20 occurrences, while the smallest font size indicates $2-5$ occurrences.

Appendix D. Evidence given by questionnaire respondents
Evidence given by questionnaire respondents that indicated change to their gardening behaviour (A), ambivalence (B) or absence of such change (C). Where present, wider declared changes, including those concerning perceptions of the environment due to engagement with BeeWatch, are also included. This evidence was collected based on answers to the eight final questions in the questionnaire:

i) Has taking part in BeeWatch changed how you see your garden area? Please explain;

ii) Has BeeWatch led to any changes in how you manage your garden area? If so, what changes?;

iii) Are there any specific parts or features of BeeWatch that have influenced this?;

iv) Have you noticed any differences (in your garden area) as a result?;

v) Do you see the changes to your garden area as positive, negative, or neutral?;

vi) Why?; 
vii) Do you feel you have learned any new skills or gained any new knowledge from using BeeWatch? Please describe;

viii) How do you feel using BeeWatch has changed your relationship with the wider environment, if at all?

A small number of spelling errors were corrected, but only in situations where these could lead to misunderstanding the response. A participant and 'knowledge category' identifier ( $K=$ knowledgeable, $L K=$ less knowledgeable, $B R=$ Biological Recorder; see main text for how these were distinguished) is provided in brackets for each set of quotes.

\section{A. Evidence for questionnaire respondents with a positive change to their gardening behaviour.}

\footnotetext{
"Yes more aware of bees and looking more closely at them" and "More aware of plants they seem to favour" (6352794497, LK).

"Yes - I am more aware of planting to attract Bees" (6330197600, LK).

"Yes, we've become more aware of the plants the bees are visiting"; "Yes, we've added more bee-friendly flowers to those we already had and tried to extend the season" and "it's become less tidy, deliberately" and "we enjoy watching the varied mix of wildlife that uses our garden" and "It's added to my interest in the flora and fauna that surrounds us" (6327128552, LK).
}

"Yes I have grown some plants from seed to increase the number of native species in the garden to better support bees. I will continue to do this" and "I try to plant with succession in mind so that there are flowers available for as long as possible during the year. More areas of the garden have been left 'wild' and we have place insect hotels in the garden. We did not remove a bees nest which was built by bees in a rockery in our garden" and "I have a greater interest in the environment. Friends have become interested too" (6327083565, LK).

"Yes - Greater awareness" and "plant bee friendly shrubs \& flowers" and "Increased awareness" and in response to the question regarding environmental perception change: "Use of Pesticides" (6322466499, LK).

"Yes, I plan to make it more bee friendly" and "Plan to plant more flowers" (6321848349, LK).

"Been planting more bee friendly plants and leaving a wild garden patch" and "More pollinators for fruit and veg" and "More sympathetic planting" and "Leaving wild plants/weeds in situ" (6321706226, LK).

"Yes, it makes me more aware of types of bees and encourages me to look out for new and different species" and "I make sure that any new plants are favourites of the bee" and "As there are more bees around - they are having a difficult time at the moment and it's great to encourage them" and "Just making me more aware and increasing my curiosity" and "When I go for walks I like to apply my new found knowledge" (6321597736, LK).

"I do plant more flowers" (6321496854, LK).

"Made it more bee friendly" and "Increased herbs" (6321452740, LK).

"Yes - my garden is too big, hard to maintain and becoming very bedraggled BUT the number of different bees keeps increasing so that justifies my neglect... doesn't it?" and "I encourage/don't discourage plants that I see the bees enjoy, and also now manage my 'lawn' and roadside verge with twice-yearly cutting to allow wildflowers - which I am also trying to plant" and "It's a lot more messy and bedraggled!!!" and in response to the question regarding environmental 
perception change: "Not precisely - more the feeling that I'm not the only oddball that think that encouraging bees matters!" (6321434910, LK).

"I've planted bee friendly plants and enjoy watching the bees visit. Next year I hope the Camelia and Weglia will flower" and "I will add bee homes into the garden and a lot more flowers" and "It's great to have diversity and to do something to help" (6321293358, LK).

"Yes, I now have a pair of small binoculars on my windowsill" and "It is less tidy now and I have log piles and bumblebee houses. I have planted more trees" and "I now only buy single flower plants" and "It is more enclosed, sheltered and the flowering period has extended far into autumn and winter" and "It is much more wildlife friendly and the flowering period extending into autumn and winter allows for early foraging queen bees to feed" and "I walk a lot slower and look closer at the surrounding vegetation" (6321264315, LK).

"Yes, I am aware of which plants are good for bees" and "I left some weeds which I know the bees like" and "More bees around the relevant plants" and "I am more aware of plants which attract bees" and "I look carefully when out and about" (6321184803, LK).

"Yes - our future planting plans will include bee watch suggestions" and "Yes - mowing regime has been adjusted to promote bee friendly flowers/weed growth" and in response to the question regarding environmental perception change: "No great change, I've always been interested in the environment, now I'm more aware of bumble bees" (6321091625, LK).

"Leave plants as long as possible when flowering and a sugared water out when loads of bees" and in response to the question regarding environmental perception change: "yes awareness" (6320975517, LK).

"More wild flowers" (6320858430, LK).

"Yes — building habitation" (6320731012, LK).

"I do now have a corner that's overgrown and has bee friendly flowers in" and "I would never have encouraged bugs and bees anywhere near my garden, now I'm encouraging them!!" (6320698565, LK).

"Larger area for pollinators" (6320680030, LK).

"Yes we made a wild area with grasses, plants herbs, flowers" (6320665765, LK).

"Yes, always planted bed friendly plants but more aware of different species which visit the garden now" and "Perhaps leave plants longer before tidying up, i.e leave foxgloves until last flower gone rather than clearing away the tall spites with top few flowers still in bloom" (6320659573, LK).

"Yes, much more aware of our bees and the flowers they like" (6320643835, LK).

"Yes leaving appropriate weeds and growing plants specifically for bees; not cutting back plants as much" and "Keeping it bee friendly and choosing plants that are bee friendly" and in response to the question regarding environmental perception change: "Not really changed but definitely more focused and encouraging others too" (6320632431, LK).

"Yes have planted more pollinator plants" (6320630673, LK).

"Yes - I've put up a solitary bee hotel" and "More inclined to think about bee friendly plants when designing/replanting areas of garden" (6320624040, LK).

"More aware now of the types of plants that attract bees and other insects" and in response to the question regarding gardening behaviour changes: "Not as yet but will implement more of the types of plants that I now know will attract bees" (6320622402, LK).

"Absolutely. I now look for plants that have pollinator friendly stickers on them when needing new plants. I have also allowed my weeds to grow from time to time to allow 
bees to forage" and "Leave the weeds to grow from time to time" and "Be more aware of my envirnment and how I can do something to make it better" (6320612501, LK).

"Trying to plant more bee friendly plants" (6293463082, LK).

"Planted some bee friendly plants" and in response to the question regarding environmental perception change: "Not particularly" (6287602958, LK).

"Yes, more aware of what bees need and therefore that is what I want to now fill my garden with. Instead of removing all the brambles in the town garden I will contain and maintain them for the bees" and in response to the question regarding environmental perception change: "Without bees we are going to come unstuck" (6282760697, LK).

"Introduced more bee friendly species, promoted by garden centres and further research from my part. I am also using this same template when creating planting schemes for clients" and "I have a better understanding and greater realisation of the number and diversity of bees in the local environment" and "I have felt the need to increase bee friendly planting in my garden" (6281792515, LK).

"Yes - have gardened to encourage them [bees]" and "Leaving as many flowering weeds as possible" and "More flowers for the bees" (6280552086, LK).

"As a general rule all new potted plants are bee friendly" and "Looking at photos noticing plant types and adding them to my list of possibles for the garden" and in response to the question regarding environmental perception change: "I am once again going out of the house exploring" (6279783269, LK).

"Yes, as I've come to see my garden as a way of supporting wildlife and the wider environment, as well as providing beauty/leisure space for myself" and "I have become much more conscious of planting bee-friendly plants" (6278492045, LK).

"I plan to plant more bee friendly plants" and " $i$ am introducing wild areas" and in response to the question regarding environmental perception change: "I bought an insect recognition book" (6275972977, LK).

"Yes, have installed a nesting box" and "Added more pot plants" and "Much more appreciative of environment" (6275288099, LK).

"I put more emphasis on choosing the right plants for wildlife and not just for their looks. I am creating different habitats within my garden" and "Planting suitable flowers for wildlife to be available all year round" and "I used to try to design and manage my garden to attract birds but now I try to encourage all wildlife" and "Creating more habitats (bug hotels, long grass, log piles, hedgehog homes, pond, banks with exposed soil, rock piles). Planting for year round nectar and for more berries and shelter" (6275141790, LK).

"Yes, it motivated me to start growing plants on my balcony" and "Yes, how to garden and look after plants" and in response to the question regarding environmental perception change: "Not really, I always appreciated the environment" (6274783883, LK).

"Yes brought in some new plants, now have a raised bed area just for wild flowers" and "Don't use weed an feed anymore have a lot of clover and daisy, and buttercups in my lawn try to leave as long as possible so they flower to give the bee's another source of food" and "Changed the way I treat my lawn, now have a raised wild flower bed plan to do another one possible a third" and in response to the question regarding environmental perception change: "More aware when we go out for a walk I now take more notice of what bee's are around" (6274764894, LK).

"Prompts me to get the correct flowers for my garden" and in response to the question regarding environmental perception change: "none" (6274717205, LK).

"I already tried to keep it bee-friendly. BeeWatch has reinforced this" and in response to the question regarding environmental perception change: "Probably not" (6274709696, LK). 
"Buy new plants specifically because they are advertised as able to attract bees" and "left it to grow wilder for the bees" (6274690826, LK).

"Making sure my garden has suitable plants for bees" and "making sure the plants are what the bees are attracted to" and "Making sure the plants are pollinator plants suitable for bees" and in response to the question regarding environmental perception change: "Better understanding all round of wildlife" (6274607137, LK).

"Always looking to add to my bee friendly planting" and "It has increased my awareness of planting and I look elsewhere whenever I see bees to check what they are feeding on" and in response to the question regarding environmental perception change: "Heightened awareness generally" (6274520627, LK).

"Planning to set up a wildflower patch in the garden with the help of On The Verge" and "It has motivated me to provide even more plants for bees including a wildflower patch" (6274484622, LK).

"Yes. I actually see my garden as a place for the creatures in it, rather than a place for me, as I already have my house. It doesn't bother me that it might look a bit untidy, I love to see all the creatures coming to it and being able to feed and live there" and "Whenever I choose plants for my garden, which is small, I always choose ones that are bee friendly" and "To me my garden is about the providing a habitat for living things, rather than just something to look at" and "I have learned lots about bees, male and female, how to identify. Before I would just see a bee, now I can tell different kinds of bees, also now telling my husband and children, who are now interested. I used to be afraid of bees, so it's pretty amazing really" and in response to the question regarding environmental perception change: "Becoming more aware of supporting habitats for a range of wildlife, and doing something about it, even if it's just in my garden at the moment" (6274428527, LK).

"Like to provide suitable plants for bees" and in response to the question regarding environmental perception change: "Supports my belief in maintaining a good environment for wild life" (6274427753, LK).

"There's a lot of clover and daisies and buttercups in one part of my lawns normally would have used a type of weed and feed now I leave it as long as possible before cutting so most have flowers on as an extra feeding area" and "Stopped using weed killer on my lawns started planting in clumps have a raised beds with wild flowers only in it so far so good oh had bee's in a old nest box for a while haven't noticed any going in or out lately so maybe they have moved on" and in response to the question regarding environmental perception change: "Yes a little bit of knowledge goes a long way" (6274356714, LK).

"Yes see it more as a resource for the environment" and "Try to spread out my pollinators through the year so there is always something to eat" and in response to the question regarding environmental perception change: "More aware of where we are lacking or doing well" $(6333998035, \mathrm{~K})$.

"I am more aware of which bumble bees like which plants" and "I cultivate more plants for pollinators" and "I've got more flowers and more bees" and "I' $m$ more observant" and "I'm more aware of my environment" (6327687846, K).

"I already was planning the garden for all wildlife but have improved my knowledge" and "Yes. More bee friendly plants" and in response to the question regarding environmental perception change: "Encourage me in what I was doing" $(6323559123, \mathrm{~K})$.

"Yes more sympathetic planting" (6321033415, K).

"Yes, to some extent. I am more aware of what we grow in the garden, and what grows around us, and if it's appreciated by the bees" and "More flowers is appreciated by both humans and bees" and "Yes, I now know better which flowers and plants are popular with the bees, and will favour planting those in the future" and in response to the question regarding environmental perception change: "A bit, but was quite interested in nature already before" $(6321006310, \mathrm{~K})$. 
"Trying to make sure have a longer flowering range of plants for bees" and "Leave bits wild" (6320895729, K).

"We have added more flowering plants etc. in tubs at the front and rear of the house. Also created a flower border" and "A higher appreciation of the Bee" and in response to the question regarding environmental perception change: "I think not" $(6320796925, \mathrm{~K})$.

"Yes; definitely need to do more e.g. increase period of flowering in the garden" and "Yes; leave a few weedy (but flowery) areas of lawn unmowed" and "Already pretty involved; but BeeWatch has definitely broadened my involvement" (6282928266, K).

"I think my garden could be more diverse and have more flowering options earlier in the season, I see bare bits and spots where I could sneak in another cotoneaster or similar" and "I've reduced willows, and plan to increase diversity. I have a planter with nettles, and husband has learned to love and leave some clover patches in the kids bit. I've struck some cuttings from a cotoneaster to give to friends" and "This has reinforced my belief that we must live in harmony with nature, and so far as poss nurture and create a space that considers the needs of the tiniest things" and "Before planting up a space, I will use the planting guide to make an informed choice to help get a useful plant for bees" $(6274659870, \mathrm{~K})$.

"I manage the maintenance and cutting of my meadows to suit the interests of the plants and insects there" and "Yes, of course. My all round knowledge of bumblebees has increased significantly and the environmental value of my land is now more fully appreciated" and "I am now more aware of the environmental importance of my meadows" (6274446086, K).

"I sometimes don't mow the grass as frequently as I can see bumble bees on the clover" and "It's made me think more about bumble bees" (6274361829, K).

"Have been interested to see which plants the bees seem to particularly like and value those plants more now" and "Not really as I have a big garden and plenty of pollinators" and in response to the question regarding environmental perception change: "Not really" (6321099522, K).

"Probably not, though I think I've been building my understanding over a number of years. Photography has probably made the most difference" and "Much happier to leave the grassy area to clover and dandelions" and "I've always been interested in the environment - I've found the bewitch identification chart the most useful tool - oh and the photos on Flickr" $(6274330659, \mathrm{~K})$.

"I try to ensure I have pollinator friendly plants for as much of the year as possible" and "I have a better understanding of bees and plants in natural areas" (6323659334, $\mathrm{BR})$.

"More aware of which flowers to plant" (6321297863, BR).

"Yes, I use wild plants as I found nursery grown plants lack nectar and pollen" (6321106670, BR).

"I was already planting for bees and other pollinators and making notes of what I see around for many years ( as well as birds and mammals) but taking part in BeeWalk and BeeWatch has resulted in me being more regimented about note taking and very pleased that my sightings are not just hiding away in my notebook but being used by conservationists" and "No real changes - just strengthened my resolve to only buy/grow pollinator plants" and "I won't buy anything unless I see a bee on it in the garden centre" and "Not BeeWatch alone, but all my surveying of bees, birds and mammals has enhanced my recording of all I see that I have done for very many years because it is now used by conservationists of various kinds to help nature - my passion" (6338683646, BR).

"Increasing effort is being applied to provide bee-friendly planting. Conversely, the garden now offers us a way of enjoying wild bees" and "Primarily through plant choice and management of the meadow areas. This is perhaps not solely driven by 
Beewatch, rather a general interest in wild bees" and "Feeling more involved, hence more conscious of issues etc." (6320971654, BR).

"Yes, I know I am growing the right plants" and "always consider planting for pollinators" and "the more bees I see then I know I am growing the correct plants and managing the garden in the right way" (6320955408, BR).

"It has made me more aware of planting nectar plants useful for pollinators including bees" (6320749795, BR).

"I avoid them when mowing and have made a habitat" and "I let the grass grow longer to encourage heather" and "More wild areas" and "I hate manicured gardens" and "less use of weed killers, more wild areas in my garden" (6320619073, BR).

"Yes we have increased bee friendly planting. I mow the lawns less frequently to maintain a cycle of useful forage" and "The lawns are scruffy!" and "I have always had a broad interest and reasonable knowledge base of the natural environment, ornithology and beekeeping. This focus is new" (6293828342, BR).

"Yes - I am more aware of the plants I am growing" and "Yes I am growing more plants suitable for pollinators" and "Increased bee awareness" and in response to the question regarding environmental perception change: "It has not" (6277792726, BR).

"Yes, as I used to be slightly disheartened looking at a patch of weeds now I manage it slightly better each year and can now view it as natural habitat" and "I now mow it more effectively at the appropriate time" and "yes, more native flowers are appearing and the grass is becoming less dominant as a result" and "yes, a greater understanding of the needs of bees" and in response to the question regarding gardening behaviour change: "it hasn't changed it just reinforced it. I know I'm not acting alone" (6277081669, BR).

"This is a new house and we are aware that the surrounding gardens are small and there is a lot of hard landscaping. We want our garden to be insect friendly" and "We always try to choose plants that are pollen rich and we are developing a meadow area (small)" and "I think I am much more bee aware" (6276324937, BR).

"Wildflower area sown this year for bees etc." (6274642567, BR).

"It has refocussed my attention on bumblebees and the plants they visit" and "I continue to plant only pollinator friendly flowers" and "It has resulted in me loving nature even more and wanting to further protect the things I love" (6274500841, BR).

\section{B. Evidence for questionnaire respondents with a neutral change to their gardening behaviour.}

"Yes, I am always checking it now for other types of bumblebees" and "I didn't really know much about bumblebees, other than they are pretty, so I have learned a lot" (6335560349, LK).

N/A (IDs 6349254661, 6326010587, 6325957550, 6325922621, 6325511647, 6324354028, 6322392353, 6321398250; all LK).

"Somewhat though I have always been interested in promoting wildlife in my garden" (6323563657, LK).

"No" and in response to the question regarding environmental perception change: "Increased awareness of different species of bumblebee" (6320719792, LK).

"Yes, I am more tolerant of bees so they can go anywhere in my garden" and in response to the question regarding environmental perception change: "It hasn't" (6322847283, LK).

"So far just my garden. I would like to use Bee Watch more but haven't due to being put off by the photos on the site when I try to enlarge them. They are a small part of the orginal. Don't know if there is something I'm not doing right" (6320915029, LK). 
"Better awareness of bees and their habitat in my garden" in response to the question regarding environmental perception change: "Not really" (6320854764, LK).

No response $(6320693849,6320684502,6303863818,6288447507,6278138342$. 6277209467, 6275554466, 6275247121; all LK).

"The plant information would be useful if I had a garden. The rest of the information is quite interesting" (6320612263, LK).

"I do not have a garden, but wish $i$ did so i could make it more wildlife friendly" (6274753204, LK).

No response $(6321641019, \mathrm{~K})$.

"Yes and no. We have always valued bees in the garden. I have taken more interest in the species (number of species, frequency of species etc.) and find I have some unusual bees occasionally (e.g. a cuckoo bee). I recognise and understand what is going on around me much better, which allows me to appreciate it more, and to marvel at it" and "A little. I recognise better the plants which attract more bees, bees in different seasons, and some plant-bee species affinities. These plants are 'more protected' in garden development" and "Not as a result of Beewatch as we were bee-friendly before" and "While I do not see any changes, I consider that decisions on garden development are better informed for maintaining bees, and so I am less likely to do something deleterious" and "Added a new dimension to my appreciation of the wider environment" (6320835320, K).

"It's probably encouraged me to continue in a direction I was going in anyway - a natural looking garden using self seeding plants" and "There's more chaos but I'm learning that I like this" (6322981436, BR).

"Not yet - potentially in siting of plants" and "Greater enjoyment of field trips, walks and garden visits by being more alert for insects" (6320651296, BR).

No response (6277670699, BR).

"We have always been conscious of how the shore land has been managed. I have been adding bee-friendly shrubs/plants over the years" and "The bees need all the help they can get and we get a lot of pleasure from it. We have also apple trees which benefit from pollinators. Our allotment also is highly dependent on bees" and "Not obviously as I have always had an interest in the wider environment" (6274499098, BR).

"Not on it's own but as part of my improving knowledge" and in response to the question regarding environmental perception change: "no" (6274437355, BR).

"It is difficult to be specific. It has helped to add to my interest in bees and in catering for them. It is not the only source of info" and "not really. I was interested in the environment before" (6274437326, BR).

\section{Evidence for questionnaire respondents with a negative change to their gardening behaviour.}

"No, as I already try to plant suitable plants for bees, butterflies and pollinators" and in response to the question regarding environmental perception change: "not really" (6326884707, LK).

"No. I was already aware and informed having been a keen gardener in the past" (6323741614, LK).

“No" (6322420131, 6321682883, 6274458906, 6274356485, 6274348333; all LK).

"No" and in response to the question regarding environmental perception change: "No" (6321415026, 6321411193, 6320699513, 6280073384, 6274738055, 6274497834, 6274339038; all LK). 
"No" and in response to the question regarding environmental perception change: "Yes" (6320695784, 6274432264; both LK).

"No. I have always attempted to create a garden that supports a diverse range of habitats for wild life, albeit without any real knowledge on the subject" (6288424373, LK).

"No - already fairly bee friendly" (6278276818, LK).

"We have always gardened in a bee friendly way as we keep bees" (6278170852, LK).

"None" and "I haven't changed anything for decades" and in response to the question regarding environmental perception change: "Made me appreciate it" and "Notice more while out and about" (6274344942, LK).

"No" and "value bees more than before" and in response to the question regarding environmental perception change: "strengthened appreciation of the natural world" (6274343353, LK).

"No" and in response to the question regarding environmental perception change: "It has given me a better understanding of the variety of native bee species and where they are found" $(6363739111, \mathrm{~K})$.

"No, pretty friendly already" and "raised awareness of variety" (6323308124, K).

"No always have tried to attract bees to my garden. Love to watch them" and in response to the question regarding environmental perception change: "Not sure it has" $(6322622515, \mathrm{~K})$.

"Not really" and in response to the question regarding environmental perception change: "No change" (6321237509, K).

"I have greatly increased the number of bee-friendly plants in my garden but this is not as a result of BeeWatch. It is mainly the result of observing which plants bees like in other people's gardens and allotments" and in response to the question regarding environmental perception change: "I don't think it has" (6321108554, K).

"No. Contact has been on a single occasion" (6320784686, K).

"No" (6320774867, K).

"No" and in response to the question regarding environmental perception change: "Not greatly, I have always been quite environmentally conscious" $(6320704026, \mathrm{~K})$.

"Not changed exactly, because I have been a BBCT member for a long time and have a strong interest in wildlife gardening and conservation, so by and large I already know a fair amount of what a garden for bees should be" and "Not yet, but as more information comes in about which plant species are the most beneficial to which bee species, I would like to improve my planting" and "It has made me more determined to do the best I can for the environment" $(6275151734, \mathrm{~K})$.

"No have tried to make garden bee friendly for many years" (6274706639, K).

"No" and in response to the question regarding environmental perception change: "No" (6274372763, K).

"I haven't made any changes yet as $i$ have always tried to garden with the bees and birds in mind" and in response to the question regarding environmental perception change: " $n o$ " (6322422562, BR).

"No" and in response to the question regarding environmental perception change: "No" (6280320456, BR).

"No. My main interest is surveys out on the local nature reserves" and "Not made any changes" and "Not much, I use it as a means of getting my IDs confirmed" (6275178815, BR). 
Ahmed, S. (2010). The promise of happiness. Durham, NC, U.S.A.: Duke University Press.

Archambault, J. (2016). 'Taking love seriously in human-plant relations in Mozambique: toward an anthropology of affective encounters'. Cultural Anthropology 31 (2), pp. 244-271. https://doi .org/10.14506/ca31.2.05.

Arts, K., van der Wal, R. and Adams, W. M. (2015). 'Digital technology and the conservation of nature'. Ambio 44 (S4), pp. 661-673. https://doi.org/10.1007/s13280-015-0705-1.

Baldock, K. C. R., Goddard, M. A., Hicks, D. M., Kunin, W. E., Mitschunas, N., Osgathorpe, L. M., Potts, S. G., Robertson, K. M., Scott, A. V., Stone, G. N., Vaughan, I. P. and Memmott, J. (2015). 'Where is the U.K.'s pollinator biodiversity? The importance of urban areas for flower-visiting insects'. Proceedings of the Royal Society B: Biological Sciences 282 (1803), pp. 20142849-20142849. https://doi.org/10.1098/rspb. 2014. 2849.

Baptista, M., Reis, P. and de Andrade, V. (2018). 'Let's save the bees! An environmental activism initiative in elementary school'. Visions for Sustainability 9, pp. 41-48. https://doi.org/10.13135/2384-8677/2772.

Blake, S., Siddharthan, A., Nguyen, H., Sharma, N., Robinson, A.-M., O'Mahony, E., Darvill, B., Mellish, C. and van der Wal, R. (2012). 'Natural language generation for nature conservation: automating feedback to help volunteers identify bumblebee species'. In: 24th International Conference on Computational Linguistics - Proceedings of COLING 2012: Technical Papers.

Bratman, G. N., Hamilton, J. P., Hahn, K. S., Daily, G. C. and Gross, J. J. (2015). 'Nature experience reduces rumination and subgenual prefrontal cortex activation'. Proceedings of the National Academy of Sciences 112 (28), pp. 8567-8572. https://doi.org/10.1073/pnas. 1510459112.

Büscher, B. and Igoe, J. (2013). "Prosuming' conservation? Web 2.0, nature and the intensification of value-producing labour in late capitalism'. Journal of Consumer Culture 13 (3), pp. 283-305. https : //doi .org/10.1177/1469540513482691.

Cameron, S. A., Lozier, J. D., Strange, J. P., Koch, J. B., Cordes, N., Solter, L. F. and Griswold, T. L. (2011). 'Patterns of widespread decline in North American bumble bees'. Proceedings of the National Academy of Sciences 108 (2), pp. 662-667. https://doi.org/10.1073/pnas.1014743108.

Chevalier, S. (2002). 'From woollen carpet to grass carpet: bridging house and garden in an English suburb'. In: Material cultures. London, U.K.: Routledge.

Clayton, S. (2007). 'Domesticated nature: motivations for gardening and perceptions of environmental impact'. Journal of Environmental Psychology 27 (3), pp. 215-224. https://doi.org/10.1016/j.jenvp.2007.06.001.

Collard, R.-C., Dempsey, J. and Sundberg, J. (2015). 'A manifesto for abundant futures'. Annals of the Association of American Geographers 105 (2), pp. 322-330. https://doi.org/10.1080/00045608.2014.973007.

Comba, L., Corbet, S. A., Hunt, L. and Warren, B. (1999). 'Flowers, nectar and insect visits: evaluating British plant species for pollinator-friendly gardens'. Annals of Botany 83 (4), pp. 369-383. https : //doi.org/10.1006/anbo.1998.0835.

Comba, L., Corbet, S. A., Barron, A., Bird, A., Collinge, S., Miyazaki, N. and Powell, M. (1999). 'Garden flowers: insect visits and the floral reward of horticulturally-modified variants'. Annals of Botany 83 (1), pp. 73-86. https://doi.org/10.1006/anbo.1998.0798.

Cresswell, J. and Plano Clark, V. L. (2011). Designing and conducting mixed-methods research. 2nd ed. London, U.K.: Sage. 
Davies, Z. G., Fuller, R. A., Loram, A., Irvine, K. N., Sims, V. and Gaston, K. J. (2009). 'A national scale inventory of resource provision for biodiversity within domestic gardens'. Biological Conservation 142 (4), pp. 761-771. https://doi.org/10.1016/j.biocon.2008.12.016.

de Castro, E. V. (1998). 'Cosmological deixis and Amerindian perspectivism'. The Journal of the Royal Anthropological Institute 4 (3), p. 469. https://doi.org/10.2307/3034157.

Degnen, C. (2009). 'On vegetable love: gardening, plants and people in the north of England'. Journal of the Royal Anthropological Institute 15 (1), pp. 151-167. https://doi.org/10.1111/j.1467-9655.2008.01535.x.

Descola, P. (1996). The spears of twilight: life and death in the Amazon jungle. New York, U.S.A.: New Press.

Dicks, L., Showler, D. and Sutherland, W. (2010). Bee conservation: evidence for the effects of interventions. Exeter, U.K.: Pelagic Publishing.

Domroese, M. C. and Johnson, E. A. (2017). 'Why watch bees? Motivations of citizen science volunteers in the Great Pollinator Project'. Biological Conservation 208, pp. 40-47. https: //doi .org/10.1016/j. biocon.2016.08.020.

Duffy, R. (2015). 'Nature-based tourism and neoliberalism: concealing contradictions'. Tourism Geographies 17 (4), pp. 529-543. https://doi.org/10.1080/14616688.2015.1053972.

Ellis, R. (2011). 'Jizz and the joy of pattern recognition: virtuosity, discipline and the agency of insight in U.K. naturalists' arts of seeing'. Social Studies of Science 41 (6), pp. 769-790. https://doi.org/10.1177/0306312711423432.

Goddard, M. A., Dougill, A. J. and Benton, T. G. (2010). 'Scaling up from gardens: biodiversity conservation in urban environments'. Trends in Ecology \& Evolution 25 (2), pp. 90-98. https://doi.org/10.1016/j.tree.2009.07.016.

Goulson, D. (2010). Bumblebees behaviour, ecology and conservation. Oxford, U.K.: Oxford University Press.

Gray, D. S. and Colucci-Gray, L. (2018). 'Laying down a path in walking: student teachers' emerging ecological identities'. Environmental Education Research, pp. 1-24. https://doi.org/10.1080/13504622.2018.1499014.

Hall, D. M., Camilo, G. R., Tonietto, R. K., Ollerton, J., Ahrné, K., Arduser, M., Ascher, J. S., Baldock, K. C. R., Fowler, R., Frankie, G., Goulson, D., Gunnarsson, B., Hanley, M. E., Jackson, J. I., Langellotto, G., Lowenstein, D., Minor, E. S., Philpott, S. M., Potts, S. G., Sirohi, M. H., Spevak, E. M., Stone, G. N. and Threlfall, C. G. (2017). 'The city as a refuge for insect pollinators'. Conservation Biology 31 (1), pp. 24-29. https://doi .org/10.1111/cobi.12840.

Haraway, D. (2016). Staying with the trouble: making kin in the Chthulucene. Durham, NC, U.S.A.: Duke University Press.

Haraway, D. J. (2008). When Species Meet. Minneapolis, MN, U.S.A.: University of Minnesota Press.

Hitchings, R. (2003). 'People, plants and performance: on actor network theory and the material pleasures of the private garden'. Social $\mathcal{E}$ Cultural Geography 4 (1), pp. 99-114. https://doi.org/10.1080/1464936032000049333.

Ingold, T. (2000). 'From trust to domination'. In: The perception of the environment: essays in livelihood, dwelling and skill. London, U.K.: Routledge.

Kopenawa, D. and Albert, B. (2013). The falling sky. Cambridge, MA, U.S.A.: Harvard University Press.

Lewis, C. and Rieman, J. (1993). Task-centered user interface design. A practical introduction. Boulder, CO, U.S.A.: Department of Computer Science, University of Colorado. 
Lorimer, J. (2007). 'Nonhuman charisma'. Environment and Planning D: Society and Space 25 (5), pp. 911-932. https : //doi .org/10.1068/d71j.

Massumi, B. (2015). Politics of affect. Cambridge, U.K.: Polity Press.

Miller, J. R. (2005). 'Biodiversity conservation and the extinction of experience'. Trends in Ecology \& Evolution 20 (8), pp. 430-434.

https://doi.org/10.1016/j.tree.2005.05.013.

Moore, L. J. and Kosut, M. (2013). 'Among the colony: ethnographic fieldwork, urban bees and intra-species mindfulness'. Ethnography 15 (4), pp. 516-539. https://doi.org/10.1177/1466138113505022.

Nowell, L. S., Norris, J. M., White, D. E. and Moules, N. J. (2017). 'Thematic analysis. Striving to meet the trustworthiness criteria'. International Journal of Qualitative Methods 16 (1), p. 160940691773384. https://doi.org/10.1177/1609406917733847.

Pawelek, J. C., Frankie, G. W., Thorp, R. W. and Przybylski, M. (2009). ‘Modification of a community garden to attract native bee pollinators in urban San Luis Obispo, California'. Cities and the Environment 2 (1), pp. 1-20. https://doi.org/10.15365/cate.2172009.

Potts, S. G., Biesmeijer, J. C., Kremen, C., Neumann, P., Schweiger, O. and Kunin, W. E. (2010). 'Global pollinator declines: trends, impacts and drivers'. Trends in Ecology \& Evolution 25 (6), pp. 345-353. https://doi.org/10.1016/j.tree.2010.01.007.

Raddick, M. J., Bracey, G., Gay, P. L., Lintott, C. J., Cardamone, C., Murray, P., Schawinski, K., Szalay, A. S. and Vandenberg, J. (2013). 'Galaxy Zoo: Motivations of Citizen Scientists'. Astronomy Education Review 12 (1), pp. 010106-010101. https://doi.org/10.3847/AER2011021. arXiv: 1303.6886.

Siddharthan, A., Lambin, C., Robinson, A.-M., Sharma, N., Comont, R., O'Mahony, E., Mellish, C. and van der Wal, R. (2016). 'Crowdsourcing without a crowd'. ACM Transactions on Intelligent Systems and Technology 7 (4), pp. 1-20. https://doi.org/10.1145/2776896.

Stengers, I. (2018). Another science is possible: a manifesto for slow science. Cambridge, U.K.: Polity Press.

Sullivan, S. (2016). 'Beyond the money shot; or how framing nature matters? Locating Green at Wildscreen'. Environmental Communication 10 (6), pp. 749-762. https://doi.org/10.1080/17524032.2016.1221839.

Threlfall, C. G., Walker, K., Williams, N. S. G., Hahs, A. K., Mata, L., Stork, N. and Livesley, S. J. (2015). 'The conservation value of urban green space habitats for Australian native bee communities'. Biological Conservation 187, pp. 240-248. https://doi.org/10.1016/j.biocon.2015.05.003.

Tsing, A. L. (2015). The mushroom at the end of the world. Princeton, NJ, U.S.A.: Princeton University Press.

- (2017). 'A threat to holocene resurgence is a threat to livability'. In: The anthropology of sustainability. New York, U.S.A.: Palgrave Macmillan U.S., pp. 51-65.

van der Wal, R., Sharma, N., Mellish, C., Robinson, A. and Siddharthan, A. (2016). 'The role of automated feedback in training and retaining biological recorders for citizen science'. Conservation Biology 30 (3), pp. 550-561. https://doi.org/10.1111/cobi.12705.

Vanbergen, A., Heard, M., Breeze, T. and Potts, S. (2014). Status and value of pollinators and pollination services. U.K. 
Wibowo, A. T., Siddharthan, A., Anderson, H., Robinson, A., Sharma, N., Bostock, H., Salisbury, A., Comont, R. and van der Wal, R. (2017). 'Bumblebee friendly planting recommendations with citizen science data'. In: Proceedings of the International Workshop on Citizens for Recommender Systems - CitRec '17. https://doi.org/10.1145/3127325.3128330.

Nirwan Sharma is a PhD student at the University of Aberdeen (now post-doctoral researcher at Bangor University) with research interests in Citizen Science and Human-computer Interaction. E-mail: n.sharma@bangor.ac.uk.

Sam Greaves is a Masters student in MSc Anthropology Environment and Development at University College London. E-mail: sam.h.greaves@gmail.com.

Advaith Siddharthan is a Reader in Computing Science at the Knowledge Media Institute, The Open University, and specialises in Computational Linguistics and Natural Language Generation, and with a longstanding interest in nature conservation. E-mail: advaith.siddharthan@open.ac.uk.

Helen B. Anderson is a Research Fellow at the University of Aberdeen with expertise in Geoinformatics and Ecology. E-mail: helen.anderson@abdn.ac.uk.

Annie Robinson is a Research Fellow at the University of Aberdeen and specialises in science communication and citizen science working on a number of projects including OPAL (Open Air Laboratories), New Zealand Flatworm survey and BeeWatch. E-mail: annierobinson@abdn.ac.uk.

Laura Colucci-Gray is a Senior Lecturer in Science Education and Sustainability Education in the School of Education. Her research is located at the intersection between teacher education, pedagogical innovation and the epistemological reflection on science, particularly with regards to the field of science-technology-studies and sustainability debates. E-mail: 1.t.gray@abdn.ac.uk.

Agung Toto Wibowo is a PhD researcher at the University of Aberdeen with research interests in Recommender systems. E-mail: wibowo.agung@abdn.ac.uk.

Helen Bostock is a Senior Horticultural Advisor at the Royal Horticultural Society, working notably on projects to further understanding of biodiversity in home gardens and native and non-native cultivated plants.

E-mail: helenbostock@rhs.org.uk.

Andrew Salisbury is Principal Entomologist at the Royal Horticultural Society. Providing advice and research on garden entomology.

E-mail: andrewsalisbury@rhs.org.uk.

Stuart Roberts is an Entomologist at the Bees, Wasps and Ants Recording Society specialising in bee ecology, biology and diversity, with a long track record in field work, identification, consultancy, training and dissemination.

E-mail: spmr@msn.com. 
David Slawson, Imperial College London, is the Director of Open Air Laboratories (OPAL), a citizen science partnership conducting environmental outreach at an exceptional scale (reaching $1 \mathrm{~m}$ people across the U.K. during 2007-16) and with a specific focus on people from hard-to-reach communities.

E-mail: david.slawson@imperial.ac.uk.

René van der Wal, Professor of Ecology at Aberdeen University (UoA), is an ecologist with a strong interest in nature conservation and people's roles in the ecology of a place, and works frequently in partnership with social scientists and computer scientists. E-mail: r.vanderwal@abdn.ac.uk.

\section{How to cite}

Sharma, N., Greaves, S., Siddharthan, A., Anderson, H. B., Robinson, A., Colucci-Gray, L., Wibowo, A. T., Bostock, H., Salisbury, A., Roberts, S., Slawson, D. and van der Wal, R. (2019). 'From citizen science to citizen action: analysing the potential for a digital platform to cultivate attachments to nature'.

JCOM 18 (01), A07. https:/ / doi.org/10.22323/2.18010207. 